\title{
An Exploratory Analysis of Factors Associated with Participation in Self-Directed and Traditional Marriage and Relationship Education
}

Shelece McAllister

Brigham Young University - Provo

Follow this and additional works at: https://scholarsarchive.byu.edu/etd

Part of the Family, Life Course, and Society Commons

\section{BYU ScholarsArchive Citation}

McAllister, Shelece, "An Exploratory Analysis of Factors Associated with Participation in Self-Directed and Traditional Marriage and Relationship Education" (2012). Theses and Dissertations. 2968.

https://scholarsarchive.byu.edu/etd/2968

This Thesis is brought to you for free and open access by BYU ScholarsArchive. It has been accepted for inclusion in Theses and Dissertations by an authorized administrator of BYU ScholarsArchive. For more information, please contact scholarsarchive@byu.edu, ellen_amatangelo@byu.edu. 
An Exploratory Analysis of Factors Associated with Participation

in Self-Directed and Traditional Marriage

and Relationship Education

Shelece McAllister

A thesis submitted to the faculty of

Brigham Young University

in partial fulfillment of the requirements for the degree of

Master of Science

Stephen F. Duncan, chair

Dean M. Busby

Alan J. Hawkins

School of Family Life

Brigham Young University

April 2012

Copyright (C) 2012 Shelece McAllister

All Rights Reserved 


\author{
ABSTRACT \\ An Exploratory Analysis of Factors Associated with Participation \\ in Self-Directed and Traditional Marriage \\ and Relationship Education \\ Shelece McAllister \\ School of Family Life, BYU \\ Master of Science
}

Although self-directed marriage and relationship education (MRE) has the potential to reach a larger or different audience than traditional MRE, little has been done to examine the characteristics of those who access self-directed materials. This study examined individual, couple, family, and sociocultural context variables that predicted participation in both selfdirected and traditional MRE programs. A series of logistic regressions were conducted using SPSS 19.0. Different factors predicted participation for each intervention. For self-directed programs, those who were older, more educated, more religious, less materialistic, whose partners were more neurotic, who had been dating for a shorter amount of time, and who had poorer relationships with their mothers were more likely to participate, while a wider range of factors predicted participation in traditional programs. Family life educators should consider creating self-directed materials designed to reach a wider audience.

Keywords: marriage and relationship education, marriage preparation programs, self-directed. 


\section{ACKNOWLEDGEMENTS}

I could not have completed this thesis without my family's support and encouragement every step of the way. I am grateful for their patience and love both throughout my life and especially during my time in this program. I am also grateful for my wonderful advisor Dr. Stephen Duncan and the help and guidance he has provided me over the last few years. He has always been willing to bend over backwards to assist me with my work, and I could not have done this without him. I especially want to express my gratitude for his patience and kindness as I adapted to the program and sought to learn all the details necessary to be a good graduate student and research assistant. I also acknowledge the other members of the BYU School of Family Life faculty, most especially those on my committee, Dr. Dean Busby and Dr. Alan Hawkins, as well as Dr. Jeremy Yorgason and Dr. Joseph Olsen. All have been more than willing to answer my many questions during this process and provide guidance and aid as I learned statistical methodology.

I would also like to express my appreciation for the other graduate students in the program for their continued emotional and academic support as we worked together in the graduate lab. Truly, obtaining an education is a team effort, and I am grateful for their encouragement and support when the going got tough. 


\section{Table of Contents}

An Exploratory Analysis of Factors Associated with Participation in Self-Directed and Traditional Marriage and Relationship Education............................................................ 1

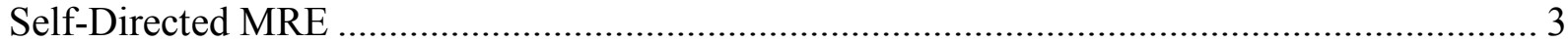

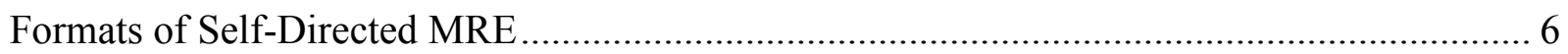

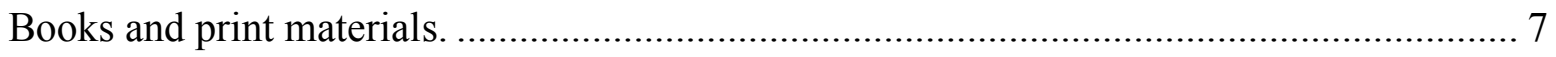

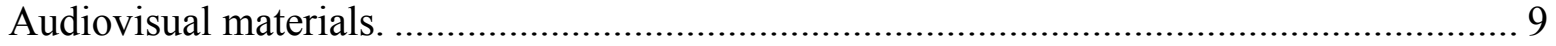

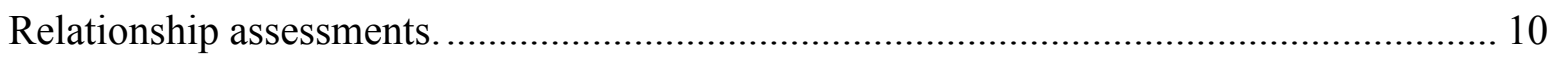

Distance learning and flexible delivery programs. ....................................................... 11

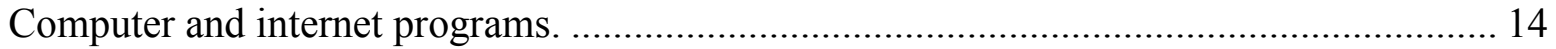

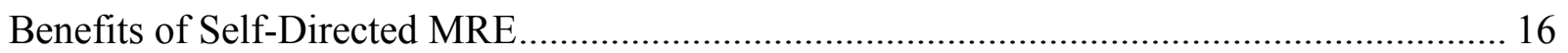

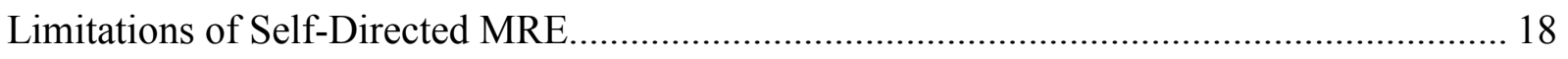

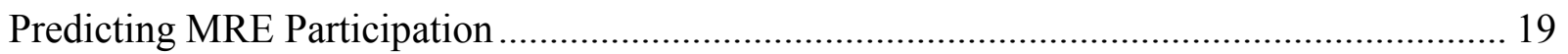

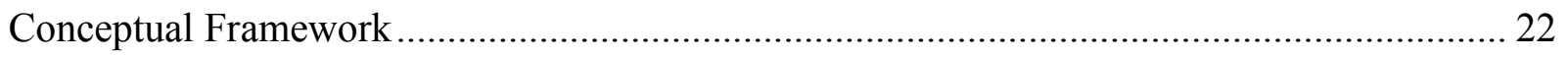

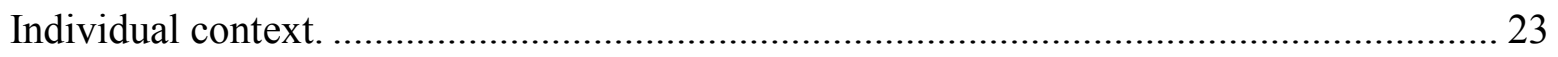

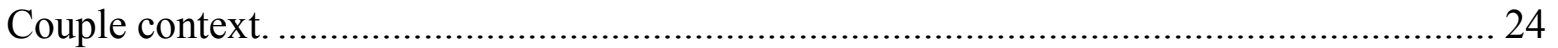

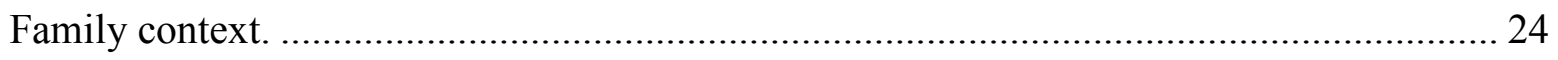

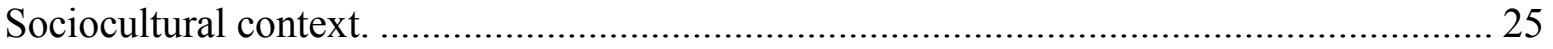

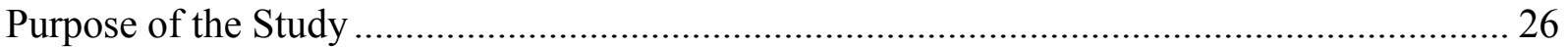

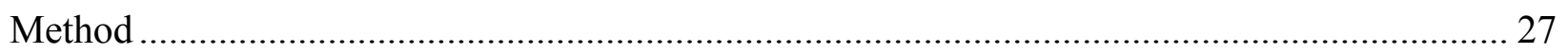

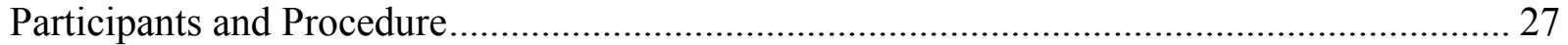

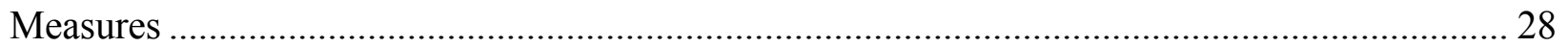

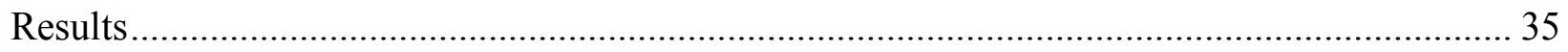

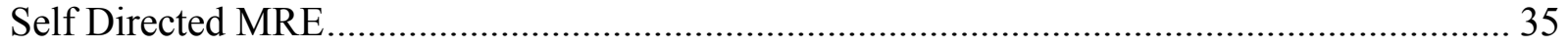

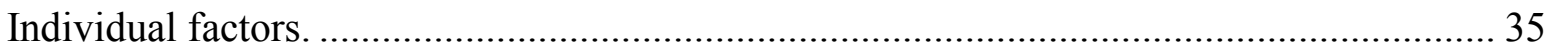

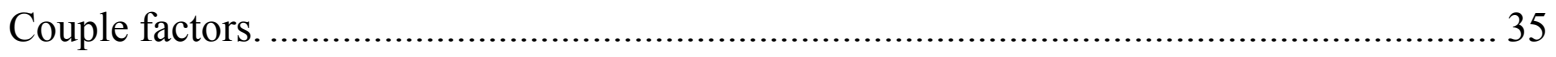

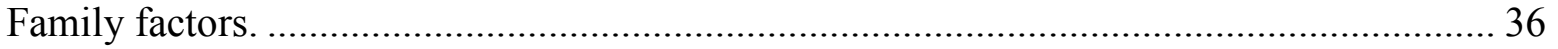

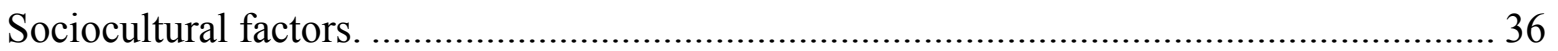

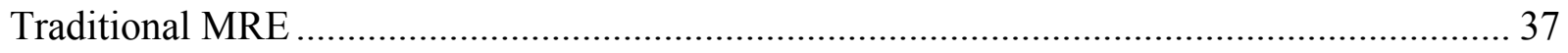

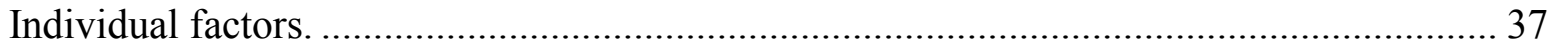

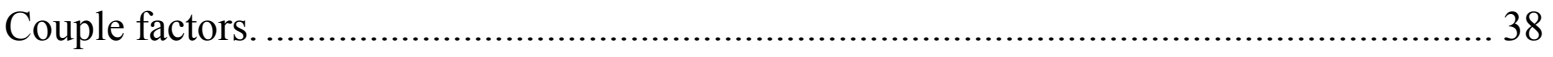




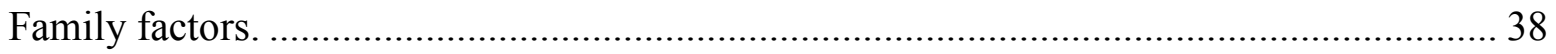

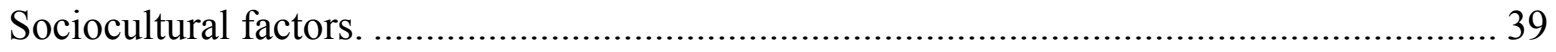

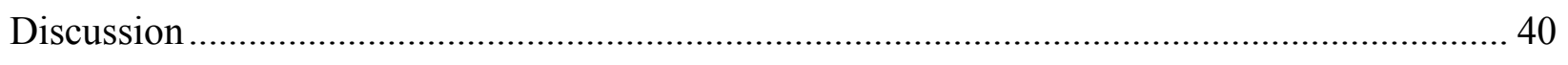

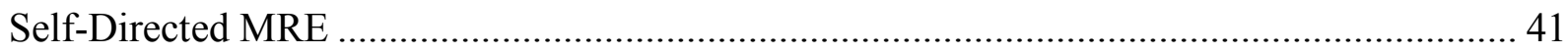

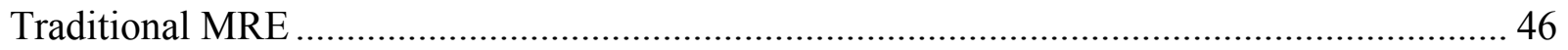

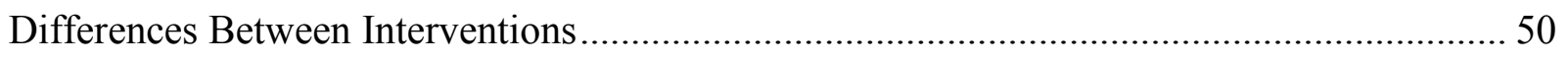

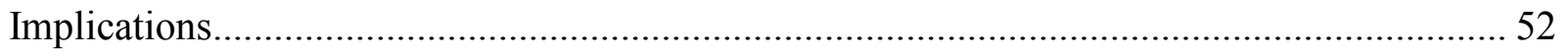

Limitations and Directions for Future Research .................................................................. 54

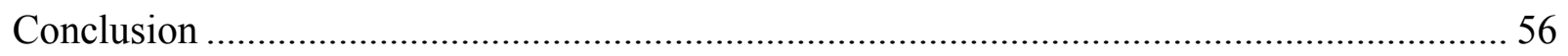

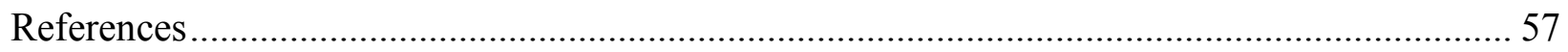

Table 1. Logistic regression coefficients, standard errors, Wald statistics, and odds ratios......... 67 


\section{An Exploratory Analysis of Factors Associated with Participation in Self-Directed and Traditional Marriage and Relationship Education}

At a time when roughly $40-50 \%$ of American marriages are expected to end in divorce (Wilcox \& Marquardt, 2010), efforts to increase marital satisfaction and stability are crucial. Research findings show that attending marriage and relationship education (MRE) can improve marital quality and communication for couples (Hawkins, Blanchard, Baldwin, \& Fawcett, 2008), as well as lower their divorce rate (Stanley, Allen, Markman, Rhoades, \& Prentice, 2010). Despite these potential benefits, however, MRE programs are poorly attended. A recent random survey across four states found that only $44 \%$ of couples married since 1990 had participated in premarital education (Stanley, Amato, Johnson, \& Markman, 2006). Further, it appears that atrisk couples, who perhaps could receive the greatest benefit from MRE, are underrepresented in MRE participation (Doss, Rhoades, Stanley, Markman, \& Johnson, 2009; Halford, O’Donnell, Lizzio, \& Wilson, 2006), although recent programming efforts in the last five years have succeeded in reaching more couples at risk (Hawkins, 2011).

Traditionally, MRE is presented as a class or workshop in a community or religious setting. It may be that in today's busy world, traditional classes are not an ideal option for many couples to attend. Indeed, Blair and Cordova (2009) found that perceived barriers to involvement in relationship education affected the likelihood of women's attendance in such programs. Such barriers may include time required to attend as well as the financial cost of participation. These researchers suggested that programs that are more convenient and accessible may attract greater attendance.

Other avenues to education exist besides traditional classroom learning. Self-directed MRE exists in various forms, such as books (Doss, Rhoades, Stanley, \& Markman, 2009), 
websites (Duncan, Steed, \& Needham, 2009), flexible delivery programs (Halford, Moore, Wilson, Farrugia, \& Dyer, 2004), and internet assessments (Halford et al., 2010). By definition, self-directed MRE is more easily accessible and convenient than traditional educational methods. Many adults may prefer self-directed psychological education, available at any time or place the participant desires, over traditional face-to-face interventions (Taylor, Jobson, Winzelberg, \& Abascal, 2002).

Technological advances such as the internet make it easier than ever to disseminate selfdirected education (Taylor et al., 2002), and more programs continue to develop. Some traditional classroom MRE programs are expanding into the realm of self-directed education. For example, a full internet version of PREP is in development (Markman, Rhoades, Delaney, White, \& Pacifici, 2010). As self-directed MRE continues to expand, so must our understanding of its potential and benefits. Most of the literature on self-directed MRE focuses on its effectiveness. However, little has been done to examine what characteristics predict participation in selfdirected education. Understanding the audience accessing self-directed education not only allows us to craft better materials to meet their specific needs (Duncan \& Goddard, 2011), it also gives us an understanding of whether self-directed education is reaching a different group than traditional classroom MRE. Accordingly, the purpose of this study is to identify individual, couple, family, and sociocultural factors that predict participation in self-directed MRE.

My literature review will cover the existing research on the topic of self-directed MRE. First, I will define MRE and more specifically self-directed MRE, and review empirical studies suggesting that self-directed MRE can be effective in improving couples' relationships. Some programs are more effective than others. Because delivery format is a factor which could influence effectiveness, I will next describe various delivery formats of self-directed MRE. All 
formats of self-directed MRE share some unique benefits and limitations when compared to traditional MRE; these will be discussed next. However, these unique benefits and limitations may depend in part on who is accessing these programs. Accordingly, I will discuss research predicting participation in self-directed MRE. Because there is little research in this area, I will also discuss studies which predicted participation in MRE as a whole. Finally, I will explain the conceptual framework for my study.

\section{Self-Directed MRE}

Fincham, Stanley, and Rhoades (2011) define relationship education as "the provision of information designed to help couples and individuals experience successful, stable romantic relationships" (p. 294). MRE differs from couple counseling in that it is "preventive and addresses relationship challenges before they become problems, in contrast to couples counseling, which is provided to couples who are already in distress" (p. 295). This is not to say that troubled couples do not participate in MRE. L'Abate (1983) defines three levels of prevention in the family field: primary, secondary, and tertiary. Primary prevention helps couples learn knowledge and develop skills to build healthy relationships before problems have developed. Secondary prevention helps couples who show signs of risk, preventing more serious problems from developing. Tertiary programs are for couples who are experiencing significant distress. For couples in this category, MRE is not enough; therapy is needed also. Most MRE programs deal with primary and secondary prevention, while couples therapy is more appropriate to address tertiary prevention (Duncan \& Goddard, 2011).

Self-directed MRE programs are educational interventions "initiated and participated in by the couple...with little or no external professional intervention" (Duncan et al., 2009, p. 163). Couples may complete these programs in their own home or in any location of their choosing, 
with little or no direct contact with an educator. The lack of direct contact does not mean that professionals are not involved in self-directed MRE; self-directed MRE programs are crafted by researchers, educators, and therapists, but these programs are typically disseminated without these professionals being present or in contact with participants. A great variety of self-directed MRE programs exist, ranging from such formats as self-help books (Doss, Rhoades, Stanley, \& Markman, 2009), websites (Duncan et al., 2009), flexible delivery programs (Halford, Moore, Wilson, Farrugia, \& Dyer, 2004), and internet assessments (Halford et al., 2010), among other types. Self-directed MRE programs also vary in their intended audience; some programs are designed for married couples in general, while other programs are designed for more specific audiences such as newlyweds, couples considering marriage, religious couples, or couples of specific ethnicities. In recent times, the internet has revolutionized information dissemination (U.S. Department of Commerce, 2010) so that there is an increasing expectation that information will be available at any time and from any place (Casey \& Halford, 2010). I expect that this shift in how knowledge is shared will lead to the creation of more self-directed MRE programs.

Studies done on the effectiveness of self-directed MRE suggest it can be an effective method of educational dissemination. A recent meta-analysis by McAllister, Duncan, and Hawkins (in press) examined the efficacy of self-directed MRE programs as compared to traditional MRE programs and blended programs (those which combined elements of both selfdirected and traditional formats). While overall, self-directed programs produced a smaller effect size than traditional or blended programs, the study provides evidence that self-directed MRE can improve couples' communication skills. A study by Duncan et al. (2009) compared a selfdirected MRE intervention given online to a traditional classroom course. Specifically, those in the online intervention were asked to read certain articles on the Forever Families website 
(http://www.foreverfamilies.byu.edu ) and to participate in article-based activities. The researchers found no difference in the magnitude of change produced by the two interventions. Halford et al. (2004) found that the flexible delivery program CoupleCARE resulted in increases in relationship satisfaction, relationship stability, and relationship self-regulation. Even brief selfdirected programs may have an impact. Braithwaite and Fincham (2007) developed a short computer based version of the Prevention and Relationship Enhancement Program (PREP) called ePREP. The program can be completed in an hour's time. The initial study found that ePREP improved relationship functioning 8 weeks after the intervention, and follow-up research found that benefits from ePREP were still present 10 months after the intervention (Braithwaite \& Fincham, 2009). These benefits were still present even if participants had experienced a breakup during this time; they seemed to carry their new skills forward into their new relationships.

A study by Duncan, Childs, and Larson (2010) took a more global approach to understanding self-directed MRE. Participants in the RELATE questionnaire were asked to report whether they had been or were currently involved in four types of MRE programs: classes, community/church-based workshops, counseling, or self-directed programs. Those individuals who had participated in MRE were then asked to rate how much improvement they had experienced due to MRE interventions; specifically, participants reported improvement in the areas of individual attitudes, couple communication, and social context. Self-directed interventions were found to produce the most change in individual and couple contexts when compared to the three other interventions. Participants were also asked to rate the overall helpfulness of the MRE interventions. On a Likert scale of 1 to 5 , with 5 representing the most helpful interventions, the mean score for self-directed programs was 4.14. In comparison, the mean score for classes was 4.15, for counseling, 3.93, and for workshops, 3.95. Thus this study 
suggests that self-directed interventions may rival more traditional formats of MRE in terms of perceived change and helpfulness.

Not all studies on the effectiveness of self-directed education have shown benefits. For example, the self-directed Marriage Moments program did not yield the anticipated increase in relationship satisfaction, despite the fact that participants reported the program to be helpful to their marriages (Hawkins, Fawcett, Carroll, \& Gilliland, 2006). The authors suggest that results may be due to a ceiling effect, as the couples participating already reported high levels of relationship satisfaction. Doctoral dissertations examining audio (Anderson, 1984) and computer MRE interventions (Ramsay, 1989) actually found negative effects on couple's relationships. These results may be due in part to issues with methodology for these studies. For example, in Anderson's study, the control group had higher scores at baseline than the intervention group; thus the intervention group's lower scores at post-test may have been due to pre-existing conditions between groups. Ramsay's intervention involved teaching about communication issues. The coursework may have awakened couples to communication issues that they did not realize they had, and the two-week treatment period may not have given sufficient time for the couples to resolve issues that surfaced. In any event, studies such as these do suggest caution in claiming self-directed MRE is uniformly effective. More studies need to be done to examine what makes the difference between effective and ineffective self-directed MRE programs. One potential factor impacting effectiveness is the form is which self-directed MRE is presented. I next will discuss different formats of self-directed MRE which are available.

\section{Formats of Self-Directed MRE}

Many varied formats of self-directed MRE exist. However, at this time, little evaluation work has been done to examine the effectiveness of various formats. Accordingly, we will focus 
our discussion on five formats most commonly reported in the research literature: books and print materials, audiovisual materials, relationship assessments, flexible delivery programs, and computer and internet interventions.

Books and print materials. Many books, newspaper columns, and magazine articles have been written regarding marriage and relationships. Couples frequently turn to these sources when they are seeking a self-directed form of MRE. A study by Doss, Rhoades, Stanley, and Markman (2009) followed 213 couples over the first 5 years of marriage. During that time, $36 \%$ of the sample sought help for their relationship. The majority of these (64\%) turned to self-help books, as compared to $53 \%$ who turned to workshops or retreats, and $39 \%$ who turned to therapy. Of those who reported reading self-help relationship books, $51 \%$ reported that they turned to the books before seeking any other kind of assistance. This study suggests that many couples turn to print materials for relationship help, often before pursuing any other option. Print materials may also be used as a follow-up to a traditional intervention. Wilson and Halford (2008) followed participants in their CoupleCARE intervention for six months after the intervention was completed. When participants were asked if they had accessed any additional resources after CoupleCARE, $42 \%$ of women and $21 \%$ of men reported reading self-help books, and $21 \%$ of women and $16 \%$ of men reported reading magazine articles, while only 3 women and 2 men in the overall sample reported attending a workshop.

Print materials can also be used as part of a more comprehensive self-directed MRE intervention. The CoupleCARE program features a guidebook, a DVD, and weekly calls from a professional. When participants were asked to rank which portion of CoupleCARE was most helpful, the guidebook was most frequently nominated, followed by the DVD and then the phone calls (Wilson \& Halford, 2008). Further, when participants were asked if they had reviewed the 
CoupleCARE materials after program completion, 15 women and 11 men (out of a total of 47 couples) reported viewing the guidebook again at least one time, but only 2 women and 1 man had reviewed the DVD. The print format appears to be more accessible as a reviewable resource as opposed to an audiovisual format.

Print materials are easily accessible and widely distributed; however, not all print materials are equal. While some books and print materials teach empirically supported principles (e.g. Fighting for Your Marriage, Markman, Stanley, \& Blumberg, 2010), others offer more of a popular-psychology approach (e.g., Men Are From Mars, Women Are From Venus, Gray, 1993). At this time, little research has been done to evaluate the effectiveness of these various books (Doss, Rhoades, Stanley, and Markman, 2009). Some evidence does exist that books can be effective as a form of MRE, however. A study by Gottman, Ryan, Swanson, and Swanson (2005) compared five brief interventions; specifically, the interventions were compared in their ability to enhance positive affect during couple conflict. Three interventions involved varied dosages of workshops, one featured workshops and therapy, and the fifth involved couples reading Gottman's (1999) The Seven Principles for Making Marriage Work. Reading the book did significantly increase a husband's ability to influence his wife with positive affect, suggesting that even the simple act of turning to a book can improve couple relationships. However, it is of note that couples in the book intervention also received "up to three hours of telephone consultation with a doctoral student in clinical psychology" (p. 165), so the intervention was not wholly self-directed, and it is not possible to separate out the effects of the book versus the effects of the telephone consultation. A more recent study by Busby, Ivey, Harris, and Ates (2007) examined three different interventions for couples. One group was assigned to a workbook-only condition, in which each couple received a workbook to be completed during a 
six week period. The other two groups consisted of an unstructured therapist directed program and an assessment based relationship program. For the therapist group, scores were the same between pretest and posttest, but dropped at the six month follow-up. The assessment group showed scores that improved across time. At six month follow-up, this group was significantly better on the problem areas scale than both of the other conditions; this group was also significantly better than the therapist-directed group on relationship satisfaction and communication. Participants in the workbook group maintained their high level of pretest scores at posttest, and even to some degree at a follow-up six months later. The workbook group was significantly better than the therapist-directed group on positive communication. These results suggest that print materials can help couples maintain relationship satisfaction and positive communication patterns over time.

Audiovisual materials. At this time little research has been done to examine the effects of audiovisual materials alone on couple relationships, although some evaluated programs do feature audiovisual components. In some ways, this category overlaps with others, as many audiovisual materials are based off books, and more audiovisual materials are continually being created online. A dissertation by Anderson (1984) examined the impact of an audio cassette program on couple relationships. Couples who participated in the audio cassette program did not improve in comparison to a control group. A dissertation by Saiz (2001) examined the impact of a PREP video-tape and workbook. Saiz compared three groups: a self-directed group who completed the PREP materials alone, a group who completed PREP with the help of a consultant/coach, and a waitlist control group. Pre-and post-tests were conducted. Couples who watched the video experienced improvement in relationship satisfaction and couple communication in comparison to the control group. No differences were found between the self- 
directed and consultant-assisted groups. However, the study does suffer from some limitations, including a small sample size and no follow-up testing.

Relationship assessments. Relationship assessments can be administered in person, by mail, or online. These questionnaires are designed to identify couple's strengths and weaknesses in order to help them improve. Some relationship assessments are given primarily in conjunction with counseling, such as the PREPARE-ENRICH questionnaire (Olson \& Olson, 2000). Such questionnaires do not qualify as a self-directed MRE intervention because a professional guides the couple through the process. However, other questionnaires exist which allow couples to take the assessment and review the results on their own, or at least with only limited contact from an educator or counselor. These relationship assessments fall under the category of self-directed MRE.

Perhaps one of the most well-studied relationship assessments is the RELATionship Evaluation questionnaire (RELATE: Busby, Holman, \& Taniguchi, 2001) offered through Brigham Young University. RELATE is a 300+ item questionnaire which can be accessed online. Each partner completes the questionnaire separately. When they have finished, couples are immediately able to download a PDF copy of their results to review with one another. A recent study by Larson, Vatter, Galbraith, Holman, and Stahmann (2007) compared three intervention groups: couples who participated in RELATE on their own, couples who participated in RELATE and attended one session with a therapist to interpret their results, and a control group. Couples with therapist assistance showed the most improvement. After an initial drop in relationship satisfaction, self-interpretation couples experienced improvement over time. These results suggest that taking a relationship assessment without an educator's assistance can still be beneficial to couple relationships. Research by Worthington et al. (1995) also supports 
this idea. Worthington et al. distributed a relationship questionnaire. Participants were then divided into two groups: those who received written feedback only on their results, and those who received feedback from a therapist. The researchers found that while the therapist feedback group experienced stronger improvement in dyadic satisfaction and commitment, the writtenfeedback-only group experienced relationship improvement without ever meeting with a professional.

Halford et al. (2010) compared couples who participated in RELATE with couples who participated in RELATE and CoupleCARE (a flexible delivery MRE program). Couples who participated in both RELATE and CoupleCARE experienced the greatest decrease in negative communication. Women who participated in both RELATE and CoupleCARE also experienced a greater increase in relationship satisfaction than women who participated in RELATE only; however, this relationship was not found for men. Thus, a relationship assessment may be more helpful when it is supplemented with additional educational materials. However, by itself, RELATE demonstrated small increases in relationship satisfaction and decreases in negative communication, which suggests that even when RELATE is accessed alone, it can help couples improve their relationships.

Distance learning and flexible delivery programs. MRE is sometimes available through distance learning courses distributed by universities or other educational institutions. MRE is available as a university course at many universities. For example, a study by Johnson (2011) examined a university course called "Intimate and Family Relations" offered by the University of Montana. While this class does not focus solely on marriage, the relationship skills taught help prepare individuals to build strong marriages in the future. Other classes exist with a strong marriage emphasis, such as the "Marriage Preparation" class taught at Brigham Young 
University. Some universities offer self-directed versions of these types of courses as part of their distance learning programs. For example, Utah State University offers a web-based distance learning marriage preparation course called "Saying I Do" (Marshall, 2005). At this time, little (if any) research has been done to examine the effectiveness of distance learning university MRE. This is an area which deserves further attention in the literature.

Additional MRE programs known as flexible delivery programs are also available. Perhaps one of the most frequently studied is the Couple Commitment and Relationship Enhancement (CoupleCARE; Halford et al., 2004; Halford et al., 2010; Wilson \& Halford, 2008) program, which is based out of Australia. CoupleCARE is a six unit self-directed intervention. Couples are given a workbook and a DVD with curriculum materials. They are encouraged to work through one unit each week. At the end of each unit, they participate in a brief telephone call with an educator. The educator checks up on their progress, and also addresses any questions or concerns they may have (Halford et al., 2004; Halford et al., 2010). Within CoupleCARE, there are variations in the involvement level of educators. In some cases, educators meet face to face with couples to assist; in other cases, the only contact is through telephone or SKYPE; and one trial was conducted in which the only professional contact was through email (W. K. Halford, personal communication, October 5, 2011). I note that CoupleCARE is not wholly selfdirected, because an educator is involved in guiding the curricula. However I believe it is important to include in a review of the literature on self-directed interventions because it is an intervention that takes place out of the classroom and mostly at home. Research has provided evidence that CoupleCARE can be effective in assisting couples. Halford et al. (2004) found that CoupleCARE produced a moderate effect size for increasing relationship satisfaction, even for couples who were already highly satisfied. In addition, CoupleCARE increased women's self- 
regulation, as well as women's reports of partner self-regulation. However, this relationship did not hold when examining men's scores on the same measures. Further, CoupleCARE did not reduce negative communication in this study. Halford et al. (2010), as previously mentioned, examined a combination of RELATE and CoupleCARE. Initially, couples took the RELATE questionnaire in order to identify strengths and weaknesses within their relationships. An educator then contacted them in order to discuss the RELATE results. At this point, couples began participating in CoupleCARE. In their phone calls, the educator took particular care to point out ways CoupleCARE could help them based off their RELATE results. The study found that negative communication decreased more for couples participating in CoupleCARE and RELATE versus RELATE alone. Women in the CoupleCARE condition experienced an increase in relationship satisfaction as well, although this was not the case for men.

Wilson and Halford (2008) took a different approach when studying CoupleCARE. Their focus was on whether couples engaged in the learning tasks in the program, as well as whether partners successively implemented self-change. In addition, they addressed whether couples maintained what they learned and whether they continued to use program materials after the program was completed. Participants seemed fairly engaged in the learning tasks, reporting over $90 \%$ completion of the workbook tasks, self-change plans, and DVD units. Participants reported moderate to high levels of self-change based on the intervention. At six month follow up, 38 couples ( $81 \%$ of the sample) responded, and all of them were still using skills learned from the program. Sixty-three percent of men and $63 \%$ of women reported using communication skills, $58 \%$ of women and $16 \%$ of men used conflict management skills, and $39 \%$ of men and $24 \%$ of women reported using intimacy and caring skills. At six months, about half of all participants reported that they had consulted either the workbook or DVD again since the program had 
ended. Taken together, these results suggest that CoupleCARE succeeds in engaging its audience, in inspiring self-change, and in teaching skills that are retained over a period of some months.

Computer and internet programs. I list this format last as it is a format through which all other forms of self-directed MRE can be delivered. Fincham et al. (2011) have noted "A visit to any campus will show that today's emerging adults live in a very real digital world... Relationship education must adapt to this reality to be viable as a public health intervention" ( $p$. 306). I anticipate that this format of self-directed MRE will continue to grow in popularity. Braithwaite and Fincham (2011) have said: "as society increasingly begins to inhabit virtual worlds, the demand for computer-based interventions... will only increase" (p. 130). At this time, some of the traditional education programs such as PREP (Braithwaite \& Fincham, 2007; Braithwaite \& Fincham, 2009; Markman et al., 2010) and PREPARE/ENRICH (Olson, Larson, \& Olson-Sigg, 2009) are developing or have developed online versions of their interventions. In addition, new online programs are being developed all the time. A recent example is the Power of Two website (Kalinka, Fincham, \& Hirsch, 2012), the only online program to be funded through the federal government's Healthy Marriage Initiative. The invention of smart phones has opened up an entirely new way to share MRE. Some MRE approaches have now created downloadable apps for smart phones - for example, it is now possible to download Gottman's Love Map as a smart phone application.

It appears that self-directed MRE offered through the mediums of computers and the internet can be effective. Duncan et al. (2009) compared a traditional MRE program to corresponding material accessible online. Participants in the online intervention experienced positive change in relationship satisfaction and empathic communication, when compared to a 
wait-list control group. When mean scores of the traditional group and the online group were compared, no significant differences were detected. This study suggests that online education may be as effective as traditional methods of MRE. Kalinka et al. (2012) provide further evidence for internet dissemination's effectiveness. New and expecting parents who accessed the Power of Two website demonstrated improved marital satisfaction and conflict management relative to a control group.

Perhaps the computer disseminated MRE program most studied at this time is ePrep (Braithwaite \& Fincham, 2007; 2009; 2011). Participants completed an hour-long computer intervention, which was specifically a form of PREP designed to meet the needs of a college dating audience. Once a week for the following seven weeks, they were emailed a reminder to apply the principles they had learned. Despite the brevity of the intervention, participants in ePrep had better mental health outcome scores (Braithwaite \& Fincham, 2009, 2011), comparable to participants in a Cognitive Behavioral Analysis System of Psychotherapy (CBASP) group (Braithwaite \& Fincham, 2007). When participants were followed for 10 months to determine long-term efficacy, the positive benefits of ePrep on mental health outcomes persisted even if the participants experienced a relationship breakup after participation, whether or not they recoupled after the breakup (Braithwaite \& Fincham, 2009). The Braithwaite and Fincham $(2007 ; 2009 ; 2011)$ studies found differing results in impacts on couple relationships. While the 2007 study found an increase in relationship functioning, no gain was found for relationship satisfaction. The 2009 study found no significant difference between treatment and control groups for communication skills or relationship satisfaction. However, ePrep participants experienced a stronger decline in instances of physical assault in their relationships when compared to those in the control group. While it must be noted that the 
control group experienced fewer instances of physical assault at baseline than the intervention group, this still provides some evidence that brief, self-directed interventions can impact serious problems within the couple relationship. The most recent study from 2011 found that ePrep increased dedication commitment and constructive communication, as well as decreased alternatives-monitoring, physical assault, and severe psychological aggression. While the first two studies involved giving the intervention to only one individual from a couple dyad, the final study administered ePrep to both couple members. This appears to have increased its impact. At this time, ePrep has only been distributed to a college audience, which limits generalizability. Additionally, couples have not been followed farther than 10 months, thus long-term effects of the intervention are unknown.

Self-directed MRE come in a variety of formats, but all formats are accessible at any time and from anywhere. Because of this, all self-directed formats share some unique benefits over traditional MRE. The next section will discuss these unique benefits.

\section{Benefits of Self-Directed MRE}

Self-directed MRE has been called one of the most common and promising approaches to strengthening marriage (Hawkins, Carroll, Doherty, \& Willoughby, 2004). Due to its unique format, self-directed MRE programs have unique benefits over other forms of education. Hawkins et al. (2004) have said "The more accessible and familiar a setting is, the more likely it is to attract people to marriage education" (p. 553). While they were not speaking of self-directed MRE specifically, it can be argued that the most accessible and familiar setting is the home. One of the draws of self-directed MRE is that it can be undergone at any time and in any setting, even in your pajamas in the warm comfort of home. Blair and Cordova (2009) found that perceived barriers to involvement in MRE affect the likelihood of participation in such programs; such 
perceived barriers might include time required to attend a class, transportation issues for getting to the class, and financial cost of participation. Self-directed MRE's ease of access diminishes many of these barriers, thus allowing it to potentially reach a wider (or at least different) audience than traditional programs.

Other features of self-directed MRE may also serve to attract a unique audience. For example, an additional benefit of self-directed MRE is that it is lower cost than traditional MRE(Doss, 2009; Hawkins et al., 2004). Self-directed MRE does not require rental of a building in which to present a class, or the hiring of an educator to teach a set number of hours each week. Because it is cost effective, self-directed MRE is easier to disseminate than more traditional forms of education. Halford and Casey (2010) note that while a 12-hour skill-training program may prove more effective in randomized controlled trials than self-directed MRE, such a program may be difficult to deliver. Thus, in practice a self-directed intervention such as RELATE may ultimately be more effective than a 12-hour program because it has more success in reaching its target audience. However, at this time no research has been done to test whether this is truly the case.

Self-directed MRE programs are more easily tailored to couple's individual needs than traditional programs. A traditional class must consider all members' needs, but self-directed MRE can focus on the specific couple's needs. For example, in a recent study by Halford et al. (2010) referenced earlier, participants first took the RELATE assessment to identify unique strengths and weaknesses in their relationship. Then, participants completed CoupleCARE, and during weekly phone calls, an educator was able to point out specifically how the program could best be applied to the couple's unique needs. Couples find it unhelpful to work through materials 
that are not applicable to their relationship needs (Busby et al., 2007). Thus, self-directed MRE may allow couples to pick and choose what they would like to study and learn.

Despite these unique benefits, self-directed MRE also suffers some unique limitations that traditional MRE does not. The next section will discuss these limitations in more detail.

\section{Limitations of Self-Directed MRE}

As with all educational programs, there are some limitations inherent in self-directed MRE. For some couples, self-directed MRE may not be intensive enough to address their needs - they may need an educator to guide them through the education process. Silliman, Stanley, Coffin, Markman, and Jordan (2002) have noted, for example, that providing feedback to couples about their differences may create difficulties if the couple do not have the necessary conflict management skills to work through those differences, although they did not test this idea. Thus a self-directed relationship assessment may do more harm than good for some couples. While a positive experience with self-directed MRE may lead some couples to seek out more intensive MRE formats (Doss et al., 2009), a negative experience may discourage couples from seeking out further MRE when in fact they need it (Larson \& Halford, 2011).

One important limitation of self-directed MRE is the lack of direct contact with the educator and other participants. Past research has demonstrated that premarital educators make a difference in couples' relationship outcomes (Owen, Rhoades, Stanley, \& Markman, 2011). Specifically Owen et al. found that premarital programs leaders accounted for $5.2 \%$ of variability in change in positive communication, $4.5 \%$ of variability in change in negative communication, and $10.5 \%$ of variability in self-reported confidence in the future of the relationship. While this is only a small portion of variability, it could make a crucial difference for some couples. Thus the lack of educator presence inherent in self-directed MRE could lead to these programs being less 
effective for some participants. Alternatively, for some couples this could be a benefit, if the program educator is not a good fit for them personally. Outside of the pedagogical alliance between student and teacher, in a typical classroom setting, participants may benefit from interacting with other class or workshop attendees. Classroom discussion helps participants learn through making comments and listening to other participants' comments, for example (Klemer \& Smith, 1975). While self-directed programs such as websites could create some interaction between participants through methods such as online forums, these methods may not have the same effect as face-to-face classroom interaction.

Further, self-directed programs overall tend to suffer from a high attrition rate (Geraghty, Wood, \& Hyland, 2010), although little research has been done to examine whether this is true for self-directed MRE. It is possible that some couples who turn to self-directed MRE may never complete the intervention, and will not receive the full benefits. At least some contact with an educator seems to help prevent attrition. In a study of CoupleCARE, participants' most common comments were that the educator helped them focus and stay motivated to complete the intervention (Wilson \& Halford, 2008).

Beyond attrition, the issue arises of who is accessing self-directed MRE in the first place. Its potential benefits are wasted if the target audience never picks up the materials. Further, its limitations may be more severe for some couples than others. Understanding who is accessing self-directed MRE could give us greater insight into this issue, and will be discussed in further detail in the following section.

\section{Predicting MRE Participation}

Research suggests that self-directed MRE may be reaching a unique audience. For some couples, self-directed education is the first place they turn for assistance for their relationship. 
For some, it may be the only MRE accessed; for others, participation may lead to seeking MRE in more traditional forms. In Duncan et al.'s (2010) study, out of 322 individuals who reported participating in self-directed premarital education, $32.2 \%$ reported that it was the first relationship education in which they had participated. Work by Doss, Rhoades, Stanley, and Markman (2009) found a preference for self-directed education. Thirty-six percent of the couples in their sample sought help for their relationship in the first five years of marriage; of these, $64 \%$ reported turning to self-help books, as compared to 53\% attending workshops or retreats and $39 \%$ participating in marital therapy. Out of the 49 couples reporting the use of self-help relationship books, $51 \%$ turned to the books before seeking any other kind of education. It appears that some couples seek self-help resources instead of turning to the more traditional routes of classes and counseling, and even those couples who do access traditional education may also access self-directed materials.

Who are these couples? Educators frequently despair that MRE efforts do not reach the more at-risk couples that truly need it. For example, in a study by Halford, O’Donnell, Lizzio, and Wilson (2006), results suggested that high risk couples were underrepresented in premarital education. Doss, Rhoades, Stanley, Markman, and Johnson (2009) found that remarrying couples most at risk of divorce were also the least likely to seek MRE. However, their work focused on traditional educational efforts, rather than self-directed. It may be that some at-risk couples turn to self-directed rather than traditional MRE, in part perhaps because they do not want to air their relationship difficulties in public. Doss, Rhoades, Stanley, and Markman's (2009) work provides support for this idea. Their study examined factors related to seeking self-directed MRE in the form of books. They found the likelihood of reading self-help materials was significantly related to higher levels of self-reported negative communication, and marginally significantly related to 
lower marital satisfaction. Perhaps most interestingly, physical violence in the relationship was strongly predictive of turning to self-help books. Fifty-five percent of couples experiencing physical violence turned to books, compared to $12 \%$ of couples who were not experiencing physical violence. These results must be interpreted with caution as only nine couples within their study reported physical violence. Nonetheless, this research suggests that at-risk couples may be especially likely to seek out self-directed education.

Although the Doss, Rhoades, Stanley, and Markman (2009) study stands apart as the only existing study to examine characteristics of self-directed MRE participants, other research exists examining the characteristics of MRE participants in general. Morris, McMillan, Duncan, and Larson (2011) compared participants who opted into a marriage education class versus nonparticipants who chose not to participate. They found that participants scored significantly lower than non-participants on self-esteem, marital communication, relational commitment, marital conflict, marital strength, marital consensus, intimacy, marital expectations, and marital satisfaction. Further analyses sought to determine which variables were predictive of participation. Only lower levels of marital communication were found to be predictive. Although risk level was not assessed, this study supports the idea that some at-risk couples will seek out MRE as a resource to improve their relationships (DeMaria, 2005). Further, recent research has demonstrated that more disadvantaged couples are now seeking and accessing MRE; these couples generally have more at-risk relationships (Hawkins \& Ooms, 2010).

Additional research suggests that couples who are not at-risk may also be drawn to MRE. Duncan, Holman, and Yang (2007) found that valuing marriage, being kind, and being mature all predicted involvement in MRE, although they also found that perceiving relationship problems (potentially a risk factor) predicted involvement. Research by Halford et al. (2006) found that 
religious service attendance and not cohabiting with one's partner were both associated with MRE attendance. Stanley et al. (2006) found that premarital education attendance increased for couples married in a religious setting, as well as for those who were better educated. These results suggest that at-risk couples are not the only ones seeking help from self-directed MRE. Rather, healthy couples may also be attracted to such interventions, particularly those who are highly educated, religious, and who value marriage highly. While the Doss, Rhoades, Stanley, and Markman (2009) study only found a connection between at-risk couples and self-directed participation, it is likely that couples who are not at risk with some of the characteristics described above are also seeking out self-directed interventions.

\section{Conceptual Framework}

The current study follows in the footsteps of a study by Duncan et al. (2007), which examined individual, couple, family, and socio-cultural context factors in predicting participation in MRE. Duncan et al. (2007) identified these four areas of interest based on existing research from Busby, Holman, and Taniguchi (2001) and Holman and Associates (2001), which identified these four contexts as the most important for understanding premarital and marital relationships. The individual context includes individual characteristics such as age and gender, personality traits such as kindness or extroversion, and beliefs and attitudes about issues such as gender roles and the value of marriage. The couple context includes interaction patterns and processes such as communication and methods of handling conflict. The family background context considers issues such as the parent-child relationship and the quality of the parents' marriage. The sociocultural context considers variables such as socioeconomic status and race.

Whereas the Duncan et al. (2007) study examined how these factors predicted participation in any kind of marriage preparation program (including self-directed programs), for 
the purpose of this thesis, I seek to narrow the focus to examine individuals who participated in self-directed MRE specifically. Examining how factors in these areas predict self-directed MRE participation will help create a clearer picture of who is accessing self-directed education. A better understanding of the audience reached will pave the way for future research to examine whether self-directed materials truly are reaching a larger or at least different audience than traditional MRE efforts in general.

At this time, little research has been done to examine the impact of these contexts on the decision to participate in self-directed MRE, or indeed in self-directed programs of any kind. However, existing research in the field seems to support the idea that these contexts do have an impact. I will now briefly describe literature for each of the four contexts.

Individual context. As stated above, the individual context examines factors such as age, gender, personality traits, and attitudes and beliefs. Age may potentially impact self-directed MRE participation. As self-directed MRE is increasingly provided through recent technologies, it may be accessed by a younger audience than traditional programs. Prensky (2001) refers to those born before 1980 as "digital immigrants" and those born after 1980 as "digital natives." Digital natives have grown up with near constant access to information through mediums such as the internet; therefore they may be more accustomed to seeking out instant forms of self-help, such as that which self-directed MRE provides. It could be that older individuals are more likely to seek out more traditional formats of MRE.

Personality traits may also play a role in the decision to participate. Duncan et al. (2007) found that kindness and maturity predicted participation in marriage preparation programs overall. It is possible that this same pattern will extend to self-directed MRE. It may also be that self-directed MRE will attract more introverted individuals, who perhaps would not be 
comfortable in a traditional workshop or community class. Morris et al.'s (2011) study found that MRE participants tend to have lower levels of self-esteem when compared to non-participants. It could be that individuals with low self-esteem seek out MRE to help them with their relationships.

Duncan et al.'s (2007) research also found that couples who valued marriage more highly were more likely to participate. It makes sense that couples who highly value marriage would want to do all they can to improve and strengthen their marriages. It may be that couples with these attitudes will be more likely as well to turn to self-directed MRE.

Couple context. Doss, Rhoades, Stanley, and Markman's (2009) work suggests that couples with lower marital satisfaction, more negative communication, and more physical abuse in their relationships may be particularly likely to turn to self-help books. Duncan et al.'s (2007) research looking at marriage preparation programs in general found that perceiving problems in the relationship predicted participation. Morris et al. (2011) found that lower levels of marital communication were predictive of participation in MRE. Further, when current participants in MRE were compared to non-participants, participants in MRE scored lower than nonparticipants on marital communication, relational commitment, marital conflict, marital strength, marital consensus, intimacy, marital expectations, and marital satisfaction. Accordingly, I expect that negative couple processes may be related to participation in self-directed MRE. The privacy of self-directed MRE may be a particular draw for couples who do not wish to air their problems in public. Unfortunately, there is no variable included in RELATE to examine individual's desire for privacy, so we are not able to explore that idea directly.

Family context. Although Duncan et al.'s (2007) research did not find any relationship between the family context and marriage preparation participation overall, it seems this was an 
important context to include in this study when considering specific interventions and in light of allied research. It could be that due to sensitivity about family background issues, individuals from troubled backgrounds might prefer the privatized options provided in self-directed MRE to more traditional programs. Longitudinal research by Sroufe, Egeland, Carlson, and Carlson (2009) demonstrates both direct and indirect relationships between early experiences in the family of origin and later romantic partnerships. Thus, it is plausible that family of origin experiences influence the decision to seek out MRE. Those who had negative experiences in the family of origin might seek out help in order to avoid repeating the patterns of their parents. Kirk (2002) has demonstrated that children of divorce are more afraid than their peers of marital failure; individuals from such a background might thus be more apt to seek help for their relationships. It is possible that positive family of origin experiences also lead to participation. For example, if parents set an example of seeking out MRE to improve their relationships, their children may be more likely to participate in MRE themselves when they marry. At this time no research has been done suggesting a relationship between one's family of origin and participation in self-directed MRE. Accordingly, this study seeks to address that gap.

Sociocultural context. Research by Stanley et al. (2006), examining participation in premarital education, found that sociocultural factors were predictive of attendance. Couples who were married in a religious setting and who were better educated were more likely to participate, whereas couples who received public assistance had decreased reports of participation. Racial differences were also apparent in attendance with Latinos more likely than Whites to receive MRE, and Blacks less likely than Whites to do so. I note, however, that an issue here is that most MRE is made by and tested for Whites rather than members of other ethnicities; this could impact ethnic minorities' involvement. 
At this time, we do not understand why these sociocultural factors affect participation, but it may be an issue of access. Couples receiving public assistance may simply not have access to MRE; these results probably do not indicate a lack of interest on these couples' part. Due to the nature of self-directed MRE, it is often cheaper and more accessible than traditional programs; thus it may be more available to those with lower incomes or education levels. Conversely, even the most accessible self-directed MRE may still be inaccessible to these individuals. While nearly 8 in 10 Americans own a computer and have internet access (Kennedy, Smith, Wells, \& Wellman, 2008), traditionally underserved groups such as those with low income or low education levels are less likely to own or use computers (Schmeida \& McNeal, 2007). Other issues may be involved besides access, however. The less educated are probably less likely to see education as a solution to problems. While an educated individual is used to turning to books or classes to increase knowledge or to learn a new skill set, someone without an educated background may simply not think to turn to these sources. Examining sociocultural predictors of self-directed MRE participation will help us understand whether self-directed MRE is reaching these underserved groups.

\section{Purpose of the Study}

Little research has been done to examine characteristics of those who access self-directed education. Understanding factors that predict self-directed MRE participation will help educators identify the audience for such materials, which may allow them to better craft self-directed resources to meet that audience's needs. In addition, identifying characteristics of the audience reached by self-directed education may give us an understanding of whether self-directed education is reaching a different group than traditional classroom MRE. Accordingly, this study seeks to identify what individual, couple, family background, and sociocultural factors predict 
participation in self-directed MRE. In order to better understand if self-directed MRE reaches a different or wider audience than traditional MRE formats such as classes and workshops, I will also examine predictors of participation for traditional MRE and compare them to predictors for self-directed MRE.

\section{Method}

\section{Participants and Procedure}

The data used for these analyses were collected via the RELATionship Evaluation Questionnaire (RELATE: Busby et al., 2001). RELATE is a 300+ item online questionnaire designed to evaluate the relationship between romantically linked partners, helping them to identify strengths and weaknesses within their relationship. Some participants took RELATE as part of an undergraduate class, while others completed it as part of a workshop for couples. Some completed it as a part of an assessment package given by a therapist or clergy member, and some simply found it online. Partners are instructed to take the instrument separately. After completion, the couple receives a detailed printout giving them feedback on their strengths and weaknesses.

The sample included 8,239 individuals, all of whom are married, engaged, or currently in a romantic relationship. Of these, 672 individuals $(8.2 \%)$ reported current or past participation in self-directed MRE, and no participation in any other form of MRE; 1,680 individuals (20.4\%) reported participation in a traditional form of MRE (defined as current or past participation in a class, a workshop, or both), and 5,888 individuals (71.5\%) reported no participation in either form of MRE. Nearly $60 \%$ of the sample (4,914 individuals) were female, and $40 \%(3,325$ individuals) were male. The average age of participants was 29.6 years $(S D=10.1$ years), with a median age of 27 years. The ethnic breakdown of the sample was as follows: $81.9 \%$ Caucasian 
(6,753 individuals), 4.5\% Asian (367 individuals), 4.2\% African (348 individuals), 4.1\% Latino (338 individuals), $2.8 \%$ mixed/biracial (233 individuals), $1.7 \%$ other ethnicities (140 individuals), and $0.6 \%$ Native American (47 individuals). The religious breakdown was as follows: 24.7\% Protestant (2,035 individuals), 30.6\% Latter-day Saint (LDS; 2,522 individuals), 15.0\% unaffiliated (1,233 individuals), and 15.6\% Catholic (1,285 individuals), with 13.8\% belonging to another religion (1,144 individuals), and $0.2 \%$ declining to answer the question (20 individuals). Overall the sample was highly educated; $30.6 \%$ (2,525 individuals) were currently enrolled in college, $22.5 \%$ (1,855 individuals) held a bachelor's degree, and $17.0 \%(1,401$ individuals) held a graduate or professional degree. A third of the sample (2,746 individuals; $33.3 \%)$ were in a serious dating relationship, a third were engaged $(3,012$ individuals; $36.6 \%)$, and a third were married $(2,481$ individuals; $30.1 \%)$.

\section{Measures}

All measures came from RELATE. Existing research has documented RELATE's reliability and validity. For detailed information on the instrument's psychometric properties, consult Busby et al. (2001). RELATE is a large comprehensive assessment which examines more than 60 self and partner predictors of marital quality.

Two questions addressed whether participants have accessed self-directed forms of MRE. Participants were asked "Which of the following marriage preparation activities have you been involved in previously?" and "Which of the following marriage preparation activities are you currently involved in?" For participants who indicated they were married, the questions read "marriage education activities" rather than "marriage preparation." Participants could select “class," "community/church sponsored workshop," "self-directed," or "counseling." Selfdirected MRE was defined as “books, internet, home study, DVD/CD”. Participants were 
permitted to select as many interventions as they had participated in; however, for the purposes of this study, I eliminated from the sample those who had participated in multiple interventions. All respondents who reported past or current (or both) participation in self-directed MRE (and no involvement with traditional MRE) were considered to be self-directed MRE participants. All respondents who reported past or current participation in classes and/or workshops (and no involvement with self-directed MRE) were considered traditional MRE participants. Care was taken to ensure that those who participated in the past and were also participating currently were only counted once. Respondents who reported never participating in any form of MRE were also included in the sample to more clearly distinguish characteristics of those who do and do not participate in MRE.

Predictive factors were examined in the individual, couple, family, and sociocultural contexts. Sociocultural contextual factors were measured with single items; all other measures were observed scale scores created from Likert-type scales, with scores ranging from one to five. Each of these contexts is described in more detail below. All variables in each context were correlated at .6 or below (with four exceptions, noted below), indicating that multicollinearity was not an issue in these analyses.

Individual factors. Eleven factors were examined in the individual context. Personality factors included kindness, extroversion, neuroticism, and flexibility; participants were also asked to rate their partner's personalities in each of these areas. Participants were also asked to report their own religiosity, their own perceptions of the importance of marriage, and their own materialism. .

For all personality scales, response choices ranged from one, indicating "never," to five, indicating "very often." Kindness was measured with four items: “considerate," "loving," 
"kind," and "friendly." Cronbach's alpha for this scale was .77 for self and .85 for partner. Extroversion was also measured with four items, including "talkative," and "outgoing" as well as two reverse-scored items, "quiet" and "shy." A higher score indicated higher levels of extroversion. Cronbach's alpha for scale was .82 for self and .80 for partner. Neuroticism was created from three smaller scales examining maturity, anxiety, and depression. Three items addressed maturity; a sample item is "easily irritated or mad." Four items addressed anxiety: "worrier," "fearful," "tense," and "nervous." Three items addressed depression: "sad and blue," “feel hopeless," and “depressed.” A higher score on this scale indicated more neuroticism. Cronbach's alpha for the neuroticism scale was .84 for self and .87 for partner. Flexibility was measured with four items, including "open minded," "flexible," "easy going," and "adaptable." Cronbach's alpha was .74 for self and .83 for partner. A higher score indicated more flexibility. In addition, participants were asked to report their personal religiosity and their perceptions of the importance of marriage and materialism. The religiosity scale consisted of three items. Participants were asked to rate how often "Spirituality is an important part of my life," as well "How often do you pray (commune with a higher power)?" and "How often do you attend religious services?" Response choices ranged from one (indicating "never") to five (indicating "very often"). A higher score indicated higher religiosity. Cronbach's alpha for this scale was .90 . The importance of marriage was measured with six items, three of which were reverse scored. A sample item is "Being married is among the one or two most important things in life." A sample reverse scored item is "It is perfectly normal never to want to get married." Response choices ranged from one (indicating "strongly disagree") to five (indicating "strongly agree"); thus a higher score indicated that an individual valued marriage more highly. Cronbach's alpha for this scale was .82. Materialism was measured with four items, one of which 
was reverse scored. A sample item is "Money may not buy happiness in a family, but it sure doesn't hurt." The reverse scored item was "Having money and lots of things has never been important to me." Response choices again ranged from one (indicating "strongly disagree") to five (indicating "strongly agree"); a higher score indicated that an individual valued money more highly. Cronbach's alpha was .64 for this scale.

All variables in this context were correlated at .6 or below with one exception. Religiosity and importance of marriage were correlated at .71. Because these two measures addressed different concepts, both were retained in analyses.

Couple factors. Three factors were examined in the couple context. A composite positive communication variable was created from scales measuring self empathic communication and clear sending; a second composite positive communication variable was created from scales measuring partner's empathic communication and clear sending. A composite negative communication variable was also created from scales measuring self criticism, contempt, and defensiveness; a similar composite negative communication variable was created from scales measuring partner's criticism, contempt, and defensiveness. In addition, participants were asked to report their relationship stability, as well as how long they had been dating (relationship length).

The positive communication scale included 8 items, addressing clear sending and empathetic listening within the relationship. Items included statements such as "In most matters, I understand what my partner is trying to say" to address empathic communication, and items such as "When I talk to my partner I can say what I want in a clear manner," to address clear sending. Two items were reverse scored, addressing whether either partner struggled to find words to express themselves. Response choices ranged from one (indicating "never") to five 
(indicating "very often"). A higher score indicated more positive communication within the couple relationship. Cronbach's alpha for this scale was .86 for self and .90 for partner. The negative communication scale included 7 items addressing criticism, contempt, and defensiveness within the relationship. Sample items include "I use a tactless choice of words when I complain" to address criticism, and "I have no respect for my partner when we are discussing an issue" to address contempt. Again, response choices ranged from one (indicating "never") to five (indicating "very often"). A higher score indicated more negative communication within the couple relationship. Cronbach's alpha for this scale was .81 for self and .89 for partner.

The final couple context scale examined relationship stability. The three items on this scale include "How often have you thought your relationship (or marriage) might be in trouble," "How often have you and your partner discussed ending your relationship (or marriage)," and "How often have you broken up or separated and then gotten back together?" Response choices ranged from one ("never") to five ("very often"). A higher score on this scale indicated a more unstable relationship. Cronbach's alpha for this scale is .80. Relationship length was measured with two items, "How long have you and your partner been dating (If married, how long did you and your partner date before marrying)?" and (for married participants only) "How long have you and your partner been married?" Participants could choose from 11 options: "0 to 3 months," "4 to 6 months," "6 to 12 months," "1 to 2 years," "3-5 years," "6-10 years," "11-15 years," "1620 years," "21-30 years," "31-40 years," and "more than 40 years." Responses to these two items were summed into an overall relationship length variable.

Most variables in this context were correlated at .6 or below. However, self and partner positive communication were correlated at .75 , self and partner negative communication were 
correlated at .76, and partner positive communication and partner negative communication were correlated at -.63. Because I wanted to include both self and partner communication reports, and because these correlations were still below .80, all communication variables were retained in the analyses.

Family factors. Four factors were examined in the familial context: the current impact of the family of origin (FOO) on the participant and the participant's current relationships, the quality of the participant's parents' marriage, the quality of the participant's relationship with their mother, and the quality of the participant's relationship with their father.

The current impact of the FOO was measured with three items, one of which was reverse scored. A sample item is "There are matters from my family experience that negatively affect my ability to form close relationships." The reverse scored item was: "I feel at peace about anything negative that happened to me in the family in which I grew up." Response choices ranged from one ("strongly disagree") to five ("strongly agree"). Thus a higher score on this scale indicated a higher negative impact of the FOO. Cronbach's alpha was .81 for this scale. Three items addressed the quality of the participant's parents' marriage. A sample item is "I would like my marriage to be like my parents' marriage." Again, response choices ranged from one ("strongly disagree") to five ("strongly agree"); a higher score indicated a more positive perception of one's parents' marriage. Cronbach's alpha for this scale was .92. Two scales addressed the fatherchild relationship and the mother-child relationship. Each scale consisted of three items. A sample item is "My father showed physical affection to me by appropriate hugging and/or kissing." Items were worded similarly between the two scales, with only the word "mother" or "father" changing. Response choices ranged from one ("strongly disagree") to five ("strongly agree"). Higher scores on this scale indicated a better relationship with one's parents. Cronbach's 
alpha for the father-child relationship was .81, while the Cronbach's alpha for the mother-child relationship was .79 .

Sociocultural factors. Three factors were examined in the sociocultural context, specifically participant age, education, and ethnicity. Age was measured by participants reporting their date of birth. Education was measured on a continuous scale. Participants were asked to report how much education they have completed. Nine options were provided ranging from "less than high school" to "graduate or professional degree." Ethnicity was measured as a categorical variable with six options: African, Asian, Caucasian, American Indian, Latino, mixed/biracial, and other. Participants who selected "other" were given the option of specifying their race.

\section{Analysis}

I used SPSS 19.0 to conduct a series of logistic regressions in order to determine which factors were most predictive of self-directed MRE participation. Logistic regression is a statistical procedure that can be used to relate a set of variables to a dichotomous outcome variable. Its primary uses are to predict group membership and to explore relationships and strengths between variables. Dichotomous variables are nonlinear, and accordingly, logistic regression does not assume a linear relationship between dependent and independent variables. Using this analysis, independent variables do not need to be interval, normally distributed, linearly related, or of equal variance within each group (Burns \& Burns, 2008). Past research has demonstrated that when all contexts in RELATE are examined together, the couple context overwhelms the effects of the other variables (Busby et al., 2001). Thus each context was examined separately, resulting in four logistic regressions. In addition, a series of four logistic regressions was conducted in order to determine predictors of participation in traditional MRE, as a comparison point to predictors of self-directed MRE (resulting in eight logistic regressions 
in total). This allowed me to address the question of whether self-directed MRE reaches a different audience than traditional programs.

\section{Results}

Eight logistic regression analyses were conducted using SPSS 19.0. Table 1 shows regression coefficients, Wald statistics, and odds ratios for each of the analyses.

\section{Self Directed MRE}

Individual factors. For the first logistic regression, self-directed MRE participation served as the outcome variable and 11 individual factors served as predictors (self and partner kindness, extroversion, neuroticism, and flexibility; self religiosity, perception of the importance of marriage, and materialism). A test of the full model with all predictors against a constant-only model indicated that the predictors reliably distinguished between those who participated in selfdirected MRE and those who did not $\left(\mathrm{X}^{2}=95.15, d f=11, p<.001\right)$. According to the Wald criterion, three variables were significant predictors of self-directed MRE participation: partner's neuroticism $(\beta=.20, p<.01, O R=1.223)$, religiosity $(\beta=.30, p<.001, O R=1.344)$ and materialism $(\beta=-.16, p<.05, O R=.856)$.The odds-ratios for these variables indicate that having a more neurotic partner, being more religious, and being less materialistic increased odds of participation in self-directed MRE. Specifically, a one point increase in partner's neuroticism was related to a $22.3 \%$ increase in odds of self-directed MRE participation, while a one point increase in religiosity was related to a $34.4 \%$ increase in the likelihood of participating in selfdirected MRE, and a one point increase in materialism was linked with a $14.4 \%$ decrease in selfdirected MRE participation. The Nagelkerke $R^{2}$ for this analysis was .03 .

Couple factors. The second logistic regression was performed on self-directed MRE participation and six couple factors (self and partner negative and positive communication, 
relationship stability, and relationship length). Again, a test of the full model with all predictors against a constant-only model indicated that the predictors reliably distinguished between those who participated in self-directed MRE and those who did not $\left(\mathrm{X}^{2}=19.43, d f=6, p<.01\right)$. According to the Wald criterion, relationship length was the only significant predictor of selfdirected MRE $(\beta=-.16, p<.001, O R=.848)$. The odds-ratio indicated that the longer a couple has been together, the less likely they were to have participated in self-directed MRE. The Nagelkerke $R^{2}$ for this analysis was .01 .

Family factors. The third logistic regression was performed on self-directed MRE participation and four family factors (impact of the FOO, relationship with mother, relationship with father, and parents' marriage). Again, a test of the full model with all predictors against a constant-only model indicated that the predictors reliably distinguished between those who participated in self-directed MRE and those who did not $\left(\mathrm{X}^{2}=30.39, d f=4, p<.001\right)$. According to the Wald criterion, only one of the family factors was a significant predictor of self-directed MRE participation: one's relationship with one's mother $(\beta=-.10, p<.05, O R=$ .904). The odds-ratio indicated that a poorer relationship with one's mother was linked with higher odds of participation in self-directed MRE; that is, a one point increase in the quality of the relationship with one's mother was linked with a $9.6 \%$ decrease in odds of participating in self-directed MRE. The Nagelkerke $R^{2}$ for this analysis was .01 .

Sociocultural factors. The fourth logistic regression was performed on self-directed MRE participation and three sociocultural factors (education level, ethnicity, and age). Ethnicity was designated as a categorical variable; the other sociocultural factors were continuous. A test of the full model with all predictors against a constant-only model indicated that the predictors reliably distinguished between those who participated in self-directed MRE and those who did 
$\operatorname{not}\left(\mathrm{X}^{2}=112.86, d f=8, p<.001\right)$. According to the Wald criterion, both age $(\beta=.03, p<.001$, $O R=1.028)$.and education level $(\beta=.11, p<.001, O R=1.113)$ were significant predictors of self-directed participation. Specifically, being older and more educated was predictive of participation. For every year increase in age, odds of self-directed MRE participation increased by $2.8 \%$. For each increase in education level, odds of participation increased by $11.3 \%$. The Nagelkerke $R^{2}$ was .03 for this analysis.

\section{Traditional MRE}

Individual factors. The fifth logistic regression was performed on traditional MRE attendance as outcome and 11 individual factors. A test of the full model with all predictors against a constant-only model indicated that the predictors reliably distinguished between those who attended traditional MRE and those who did not $\left(\mathrm{X}^{2}=730.61, d f=11, p<.001\right)$. According to the Wald criterion, the following variables were significant predictors of class attendance: kindness $(\beta=-.15, p<.05, O R=.861)$, partner's kindness $(\beta=.23, p<.001, O R=1.255)$, partner's neuroticism $(\beta=-.20, p<.001, O R=.822)$, religiosity $(\beta=.28, p<.001, O R=1.321)$, and importance of marriage $(\beta=.51, p<.001, O R=1.660)$. The odds-ratios indicated that a one point increase in self kindness was associated with a 13.9\% decrease in odds of participation in traditional MRE, a one point increase in partner's kindness was linked with a $25.5 \%$ increase in participation odds, while a one point increase in partner's reported neuroticism was linked with a $17.8 \%$ decrease in participation odds. A one point increase in religiosity was associated with a $32.1 \%$ increase in odds of participating in traditional MRE, and a one point increase in the perception of the importance of marriage was linked with a $66.0 \%$ increase in participation odds. In other words, those who were less kind, more religious, who valued marriage more highly, and 
who had a partner who was kinder and less neurotic were most likely to participate in traditional MRE. The Nagelkerke $R^{2}$ was .13 for this analysis.

Couple factors. The sixth logistic regression was performed on traditional MRE attendance as outcome and six couple factors (self and partner negative and positive communication, relationship stability, and relationship length). A test of the full model with all predictors against a constant-only model indicated that the predictors reliably distinguished between those who attended traditional MRE and those who $\operatorname{did} \operatorname{not}\left(\mathrm{X}^{2}=209.52, d f=6, p<\right.$ .001). According to the Wald criterion, the following variables were significant predictors of class attendance: partner's positive communication $(\beta=.25, p<.01, O R=1.288)$, partner's negative communication $(\beta=-.26, p<.001, O R=0.773)$, and relationship length $(\beta=-.21, p<$ $.001, O R=0.810)$. Thus those who had partners who engaged in positive communication and less negative communication, as well as those who had been together for a shorter length of time, were more likely to participate in traditional MRE. More specifically the odds-ratios indicated that a one point increase in partner's positive communication lead to a $28.8 \%$ increase in odds of participation in traditional MRE, and a one point increase in partner's negative communication lead to a $22.7 \%$ decrease in odds of traditional MRE participation. An increase in relationship length was linked with a $19.0 \%$ decrease in odds of participation. The Nagelkerke $R^{2}$ was .06 for this analysis.

Family factors. The seventh logistic regression was performed on traditional MRE attendance as outcome and four family factors (impact of the FOO, relationship with mother, relationship with father, and parents' marriage). A test of the full model with all predictors against a constant-only model indicated that the predictors reliably distinguished between those who attended traditional MRE and those who did not $\left(X^{2}=137.13, d f=4, p<.001\right)$. According 
to the Wald criterion, all four variables were significant predictors of traditional MRE attendance: impact of FOO $(\beta=-.11, p<.01, O R=0.899)$, parents' marriage $(\beta=.11, p<.001$, $O R=1.120)$, relationship with mother $(\beta=.10, p<.01, O R=1.107)$, and relationship with father $(\beta=.08, p<.05, O R=1.078)$. Viewing one's parents' marriage as higher quality and having a higher relationship with both mother and father was linked with traditional MRE participation, while experiencing a negative impact of the FOO lead to a decrease in participation. Specifically, the odds ratios indicated that a one point increase in self-reported negative FOO impact resulted in a $10.1 \%$ decrease in odds of traditional MRE participation, a one point increase in perceived parental marital quality was linked with a $12.0 \%$ increase in odds of participation, a one point increase in self-reported relationship with mother lead to an $10.7 \%$ increase in odds of participation, and a one point increase in self-reported relationship with father was linked with a $7.8 \%$ increase in odds of participation. Nagelkerke $R^{2}$ was .03 for this analysis.

Sociocultural factors. The eighth and final logistic regression was performed on traditional MRE participation and three sociocultural factors (education level, ethnicity, and age). Ethnicity was designated as a categorical variable; the other sociocultural factors were treated as continuous. A test of the full model with all predictors against a constant-only model indicated that the predictors reliably distinguished between those who participated in traditional MRE and those who did not $\left(\mathrm{X}^{2}=283.37, d f=8, p<.001\right)$. According to the Wald criterion, age $(\beta=-.05$, $p<.001, O R=0.952)$, and education level $(\beta=-.04, p<.05, O R=0.965)$ were significant predictors of traditional MRE participation. Ethnicity trended on significance. Specifically, African Americans were less likely to participate in traditional $\operatorname{MRE}(\beta=-.50, p<.10, \mathrm{OR}=$ 0.607). The odds-ratios indicated that a one year increase in age resulted in a $4.8 \%$ decrease in the odds of traditional MRE participation, and an increase in education level lead to a $3.5 \%$ 
decrease in participation. At the trend level, being African American was linked with a 39.3\% decrease in odds of participation in traditional MRE. For this analysis the Nagelkerke $R^{2}$ was .05 .

\section{Discussion}

This study followed in the footsteps of a study by Duncan et al. (2007) which examined predictors of attending marriage preparation education. Specifically this study narrowed its focus to identify factors predictive of accessing self-directed MRE, in order to better understand the audience reached by these approaches. In addition, I examined factors predictive of accessing traditional MRE (MRE presented in classroom or workshop formats), so that I could explore whether self-directed MRE reaches a different audience than more traditional MRE formats. Factors were examined in the individual, couple, family background, and sociocultural contexts, as these four contexts have been identified in past research as the contexts most important to consider in order to understand premarital and marital relationships (Busby et al., 2001; Holman et al., 2001). The results (given in Table 1) suggest that those who are older, more educated, more religious, less materialistic, and who have been dating for a shorter amount of time are more likely to participate in self-directed MRE; having a more neurotic partner and having a poorer relationship with one's mother were also significant predictors. In contrast, a more complex pattern emerged when I examined factors predictive of traditional MRE participation (discussed in more detail below). For both interventions, being highly religious was predictive of participation. In addition, there was an association between relationship length and participation such that couples who had been together for less time were more likely to participate in a form of MRE. However, for the most part, factors predictive of participation varied between the two types of interventions. This suggests that self-directed and traditional forms of MRE may indeed be reaching different audiences. 


\section{Self-Directed MRE}

Seven factors were found to be predictive of self-directed MRE participation: age, education, religiosity, materialism, partner's neuroticism, relationship length, and relationship with one's mother. I anticipated that younger couples might be drawn to self-directed MRE since they have grown up as "digital natives" (Prensky, 2001) and thus, they might be more accustomed to seeking out instant forms of self-help, rather than waiting to participate in a class. However, the results suggest that being older predicts self-directed participation; specifically a one year increase in age was linked with a $2.8 \%$ increase in odds of participation in self-directed MRE. Arguably, the older one gets, the more one is "at risk" of experiencing anything. However, in connection with this finding, results of the logistic regressions found that higher levels of education predicted participation in self-directed MRE; a one level increase was linked with an $11.3 \%$ increase in self-directed MRE participation odds. Interestingly, it appears that traditional participants are likely to be younger and less educated.

Why would traditional MRE attract a younger audience, while self-directed MRE attracted an older audience? A majority of traditional MRE participants in the study were currently enrolled in college (52.2\%). It could be that these college students have greater access to traditional MRE because of MRE classes offered at their university, while those who have graduated can no longer access these courses, or they have to pay an additional fee to participate (versus courses included in the cost of university tuition). Furthermore, graduates may have busier schedules and thus find it more difficult to fit traditional MRE programs into their lives; thus they are more likely to turn to self-directed MRE. Another issue that could be at work here is that of privacy. The younger generation who has grown up on social media websites such as Facebook may be more open to sharing their lives than older cohorts. Those who are more 
private may be more comfortable turning to self-directed MRE in their own homes rather than attending a class or a workshop. However, in this dataset, we did not include a privacy variable - future research would do well to examine this issue.

I note that non-participants were on average three years younger than self-directed participants, and three years older than traditional participants. It is difficult to know how to interpret this result. Some of this could be an issue of maturity. Perhaps these individuals were not involved in serious relationships in their early twenties, or perhaps they were not as concerned about taking courses to strengthen their relationships. Thus they did not participate in traditional MRE in college. It may be that as they reach their early thirties, they will become more serious about their romantic relationships and thus willing to invest more in efforts to strengthen their relationships. Thus, they may seek out MRE, and turn to self-directed MRE opportunities because they are easier to fit into their schedules than traditional MRE.

It is also interesting to note that an increase in education level lead to greater participation in self-directed MRE. Research by Stanley et al. (2006) in the past found that individuals who were more educated were more likely to seek out MRE. It appears that this is the case with selfdirected MRE as well. This may be in part due to the fact that the more educated have better access to self-directed MRE curricula. They may also have more awareness of self-directed MRE that is available. It may also be that those with higher education levels have more motivation to seek out self-directed education in general.

The results also found that individuals who were more religious were more inclined to participate in self-directed MRE. Higher religiosity was also predictive of participating in traditional MRE. This is not surprising, as many MRE programs are religiously based, and past research has demonstrated that religious individuals are the most likely to participate in MRE 
(Halford et al., 2004; Stanley et al., 2006). Ellison, Burdette, and Glenn (2011) found a positive link between college women's religiosity and the value they placed on marriage as a personal goal. It could be that religious individuals place a higher priority on marriage as a life goal, and thus they are more likely to turn to MRE to strengthen their dating relationships and to prepare themselves for marriage.

Being less materialistic was another significant predictor of self-directed MRE participation. A benefit of self-directed MRE is that it may be lower cost than traditional programs (in particular because an educator does not need to be paid to be present, nor does a physical location to meet need to be acquired. Those couples who are less materialistic may be attracted to self-directed MRE more than traditional classes because they are seeking the best deal for their money's worth, rather than the most impressive (and expensive) class or workshop available. Alternatively, this could be another sign that healthier couples are more likely to turn to RELATE. Those who are less materialistic may place a higher value on their relationships than someone who places a high value on money and material things, thus they may have more motivation to seek out MRE to strengthen their relationships.

Having a more neurotic partner was also linked with self-directed MRE participation. Past research has linked partner's neuroticism to decreased marital satisfaction (Karney \& Bradbury, 1997; Whisman, Uebelacker, \& Weinstock, 2004), as well as to decreased relationship satisfaction for unmarried couples (Larson, Blick, Jackson, \& Holman, 2010). Thus it makes sense that someone with a more neurotic partner might seek out methods to improve their relationship. An interesting contrast emerges from this data, however, in that having a more neurotic partner predicted self-directed MRE participation, while having a less neurotic partner predicted participation in traditional MRE. Partners who are less disposed towards neurotic 
tendencies might be more open to the idea of attending a class or workshop. Because selfdirected MRE can take place in the home, it might be easier to convince a neurotic partner to participate in a self-directed intervention than to convince them to take the time to attend a class or workshop. An issue here could be that traditional MRE is more often experienced as a couple, rather than on an individual level. If the neurotic partner does not wish to participate in MRE, it may be easier for their non-neurotic partner to access self-directed MRE rather than attend a class alone; self-directed MRE may be more easily accessed individually while traditional MRE is often designed with the expectation that both partners will participate. My measure of selfdirected MRE, however, did not ask directly whether these programs were geared for individual or couple participation; future research in this area should determine whether there are more selfdirected MRE programs designed for individual use available than traditional MRE classes or workshops. Turning to self-directed MRE would probably be beneficial for neurotic individuals. Research examining ePrep, an hour long self-directed program accessed on a computer, found that it not only improved the couple relationship but also decreased symptoms of depression and anxiety (Braithwaite \& Fincham, 2007).

Another interesting contrast within the data emerged in the family realm. Having a poorer relationship with one's mother predicted self-directed participation, while having a better relationship with one's mother predicted traditional MRE participation. In addition, having a better relationship with one's father increases odds of participating in traditional MRE, but the father-child relationship did not play a role in predicting self-directed participation. Why might this be the case? Perhaps mothers played a role in both interventions, while fathers only impacted traditional MRE, in part due to the particular value of the mother-child attachment in young adulthood. Markiewicz, Lawford, Doyle, \& Haggart (2006) studied adolescents and young adults 
(ages 12-28) to see whether they relied on mothers, fathers, romantic partners, or peers to fulfill attachment functions. At all ages, mothers were used as a secure base more often than fathers or peers, even when participants were in a romantic relationship. Thus mothers' roles may be more prominent in making MRE decisions. The question remains why a poor relationship with one's mother would lead someone to turn to self-directed MRE whereas a good relationship leads one to traditional programs. Perhaps in part this is an issue of delivery. Someone who does not have a good relationship with their mother may have developed a sense that they need to rely on themselves to solve their own problems; thus they turn to self-directed MRE which they can use on their own to learn how to strengthen their romantic relationship. In contrast, someone who has a better relationship with their mother might feel more comfortable turning to someone else (such as a family life educator) for assistance with their relationship. More research needs to be done to explore this idea; at this time, little work has examined the impact of family factors on MRE participation.

For both self-directed and traditional MRE, those couples who had been together for a shorter amount of time were more likely to report past or current participation in MRE. Part of this may have been due to the nature of the sample. The modal relationship length was one to two years, as was the median relationship length. On the whole, these couples had not been together very long. One third of the sample were dating seriously while one third were engaged, with only one third reporting they were currently married. Duncan et al. (2010) note that according to the Stages of Change theory (Prochaska \& DiClemente, 1993), it is during the contemplation stage that people begin to be open to education (consciousness raising), and they begin to evaluate themselves in relationship to the target behavior - they decide if they want to change. As these individuals begin to contemplate whether or not their relationship should 
continue into marriage, they may be especially likely to seek out MRE. In particular, as they decide to marry and become more committed to their relationship, they may want to seek education to help them strengthen their relationship into a strong marriage. The early years of marriage include choices, such as the decision to become parents, which may also motivate couples to examine their relationship more closely and make it as strong as it can be before they venture to the next life stage.

These results should be interpreted with some caution. The Nagelkerke $R^{2}$ were small for these analyses, running between .01 to .03 . This suggests that very little of the variance in selfdirected MRE was accounted for in these analyses. Future research should examine a wider range of factors which may be predictive (this idea is discussed in more detail in the "Limitations and Directions for Future Research" section later in this paper).

\section{Traditional MRE}

In contrast to self-directed approaches, a wide variety of factors (14 total) were identified as predictive of traditional MRE. In the individual factors context, being less kind, valuing marriage highly, having a partner who is kind, and having a partner who is not neurotic predicted traditional MRE attendance. In the couple factors context, lower partner negative communication and more partner positive communication were linked with traditional MRE participation. In the family factors context, having a more positive relationship with one's mother and father and having a more positive perception of one's parents' marriage predicted traditional MRE participation, while experiencing a negative impact from the FOO decreased odds of participation. Finally, a logistic regression examining the sociocultural context found that traditional MRE participants were more likely to be younger and less educated than nonparticipants. In addition, African Americans were less likely to participate in traditional MRE 
than individuals of other ethnicities; however this finding was only trending towards significance.

Past research looking at MRE as a whole has also found a link between valuing marriage highly and choosing to participate in MRE, as well as a link between kindness and MRE participation (Duncan et al., 2007). Duncan et al.'s work also found a link between maturity (that is, the ability to control one's temper) and participation. This can be related to the finding here that decreased partner neuroticism leads to increased odds of participation, as the maturity scale was included in the neuroticism measure. However, one present finding stands in opposition to Duncan et al's research — whereas in their study, they found evidence that those who were kinder participate in MRE, in the present study, results suggested that those who were less kind were especially likely to seek out traditional MRE. Partner's increased kindness predicted traditional MRE participation, but self kindness was negatively related to participation. Further research needs to explore this discrepancy. It could be that those who are less kind feel more of a need to improve themselves in their relationships, particularly if they feel their partners are kinder than they are.

In the couple context, reporting less negative communication and more positive communication in one's partner was predictive of traditional MRE participation, while one's own communication traits were not. It is interesting that the relationship was only found for one's partner's communication and not for one's own. Past research has suggested that people are least accurate when reporting on their own traits (Rusbult, Lange, Wildschut, Yovetich, \& Verette, 2000), and that an individual's rating of their partner is most influential in predicting couple outcomes (Busby et al., 2001). Thus these results suggest that these couples have positive communication patterns overall in their relationship. More work needs to be done longitudinally 
to explore whether these communication patterns are a result of the intervention or truly a factor leading to participation. But it appears that less distressed couples are more likely to seek out traditional MRE. Past research has also come to this conclusion; at-risk couples who could perhaps benefit the most from participation are less likely to participate (Halford et al., 2006; Doss, Rhoades, Stanley, Markman, \& Johnson, 2009). While continued efforts should be made to reach out to more at-risk couples, we should not neglect those healthy couples who do seek out intervention, nor should we discount the impact MRE can have to help these couples maintain strong relationships.

Duncan et al.'s (2007) research did not identify any significant predictors in the family context. However, four predictive family factors were found for traditional MRE participation: having a more positive relationship with one's mother and father and having a more positive perception of one's parents' marriage were linked with increased participation odds, while experiencing a negative impact from the FOO decreased participation odds. Past research has demonstrated that negative FOO experiences can impact perceptions of marriage; for example, Kirk (2002) found that children of divorce were more afraid of marital failure than their peers. Thus I anticipated that negative FOO experiences would increase participation in MRE, as these individuals would want to seek help to avoid a repeat of negative FOO experiences in their own families. It could be that individuals turn to other methods besides MRE to cope with these experiences, however; for example, children of divorce cohabit at a higher rate than children from intact families (Thornton, 1991). While cohabitation is linked with a higher risk of divorce (Jose, O’Leary, \& Moyer, 2010), it is increasingly viewed in American culture as a trial run to determine whether or not the relationship could become a viable marriage. It could be that those who grew up in a negative family environment are more likely to turn to methods such as these 
to strengthen their relationship, rather than turning to MRE. It could also be that these individuals experience fear of marriage, and as they are not actively progressing towards marriage, they see no need for MRE.

Those who grew up in a positive family environment, however, may be more likely to seek out an MRE class because they have learned from their parents that marriages can be strong and fulfilling. This positive model could demonstrate the potential benefits of marriage and provide motivation to do all they can to build a marriage like their parents'. Yamauchi and Ito (2008) found that parents' marital relationships directly impact adolescents' marital attitudes. When adolescents perceive their parents' marital quality as good, it influences their dating choices. This same pattern may be occurring in adulthood courtship as well. It may also be the case that some parents participated in traditional MRE themselves and encouraged their children to do so also; future research can explore this idea further. It is interesting that a more positive relationship with one's parents was linked with participation in traditional MRE. Perhaps a healthy attachment with one's parents models a pattern for a healthy attachment relationship with one's romantic partner; thus individuals who report a good relationship with their parents are more likely to seek out traditional MRE in order to help them achieve that ideal. They may be seeking to replicate attachment relationships which they experienced in their childhood homes.

Finally, in the sociocultural context, being younger and less educated (that is, still in college rather than holding a completed degree) increased odds of traditional MRE participation. These results have already been discussed above. An additional finding was that African Americans were $39.3 \%$ less likely to participate in traditional MRE than any other ethnicity; this finding, however, only trended towards significance. Past research by Stanley et al. (2006) found that African Americans were less likely to participate in MRE than Caucasians. More research 
needs to be done to explore this finding. A confounding issue might be socioeconomic status. Stanley et al. found that those were who better educated were more likely to participate in MRE, while couples receiving public assistance were less likely to participate. A disproportionate percentage of African Americans may be less educated and less financially well off. They may look in vain for MRE programs specifically adapted for African Americans. Research by Duncan, Box, and Silliman (1996) suggests that marriage preparation programs could reach more African American young adults if programs demand fewer hours or weeks, and if they are located closer to home. Economically related barriers such as difficulty getting time off work or lack of access to transportation may impact attendance for this group. As self-directed MRE gets around some of these barriers, it may be worthwhile to craft self-directed materials specifically for this audience, in order to reach those who are not accessing traditional MRE programs.

All results for traditional MRE need to be interpreted with caution. For all four of the logistic regressions addressing traditional MRE, tests of the full model with all predictors against a constant-only model indicated that the predictors reliably distinguished between those who attended classes and those who did not. Yet the Nagelkerke $\mathrm{R}^{2}$ for these analyses was small (although bigger than those found for self-directed MRE), ranging between .03 to .13. This suggests that only a small part of the variance in traditional MRE participation was accounted for by these analyses. More research needs to done to explore additional factors that might impact the decision to participate in traditional forms of MRE.

\section{Differences Between Interventions}

Different factors emerged as being predictive of participation in self-directed and traditional MRE programs. Far more factors were predictive of traditional MRE than of selfdirected MRE. Some of this may be due to the nature of the interventions. Because traditional 
MRE tends to be more time consuming, and because it takes more effort to attend a class or workshop than to access a self-directed program, it may be that more factors must come into play to motivate the participant to attend a class versus pick up a self-help book. For example, it is of interest that valuing marriage highly was predictive of traditional MRE participation, yet this was not the case for self-directed MRE. It could be that because traditional MRE takes more effort to participate, those who are motivated by a strong value of marriage are more likely to attend than those without this motivation; however, people with various views on the institution of marriage will make the simpler effort to read a self-help book or access an MRE website. I have already discussed the differences between interventions in the factors of age, education level, partner's neuroticism, relationship with one's mother, and ethnicity, as well as similarities in the area of relationship length and religiosity. Below I will discuss the remaining differences in factors between self-directed and traditional MRE.

In the couple context, having less negative communication and more positive communication from one's partner predicted traditional MRE participation, but couple communication did not predict participation in self-directed MRE. This was contrary to my expectations that self-directed MRE would attract couples caught in negative couple processes (i.e. poor communication). Again, this may relate to the fact that traditional MRE is often experienced as a couple. While couples with greater communication difficulties could arguably benefit more from traditional MRE than a couple with fewer problems, it is likely that couples who communicate better would be more open to attending a class or workshop together, precisely because they are getting along. Because the decision to participate in self-directed MRE is less likely to be a joint decision, perhaps communication and couple processes are less 
likely to impact it. Future research should examine whether self-directed MRE is more likely to be accessed on the individual rather than the couple level.

In the family context, perceiving one's parents to have good marital quality and having a good relationship with one's mother and father were predictive of traditional MRE participation, while experiencing a negative impact from the FOO decreased odds of participation. Only one family factor predicted self-directed MRE participation: having a poorer relationship with one's mother. Thus FOO factors did not play as large of a role in self-directed MRE participation as in traditional MRE participation. FOO factors are distal from the couple relationship, and it could be that for the most part their impact does not reach forward to influence a choice to access selfdirected MRE, whereas FOO still play a valuable motivating role in seeking out more time consuming forms of MRE such as a class or workshop. More research needs to be done to understand this relationship.

The factors from the sociocultural context have already been discussed in the SelfDirected MRE and Traditional MRE sections above.

\section{Implications}

This study provides evidence that different factors influence participation in self-directed MRE versus traditional MRE classes and workshops. This suggests that we need to continue to provide both types of interventions, in order to reach the largest audience possible. Perhaps of the most interest is that self-directed MRE appears to be reaching an older, more educated audience, while traditional MRE is reaching a younger audience primarily still in college. This suggests that college students may take advantage of MRE courses offered through their university; thus it would be of value to continue to provide these classes and increase such offerings. It may also be of value to tailor more self-directed MRE to reach this younger 
audience. Young adults of today increasingly rely on new technologies such as social networking. I echo Fincham et al. (2011) that efforts must be made to provide self-directed MRE in these formats if relationship education is "to be viable as a public health intervention ( $p$. 306)." Younger audiences may not be as aware of MRE options available to them. Awareness precedes use. Reaching out to them using methods such as social networking may be a way to bring more of them to an awareness of programs they can access. In addition, efforts should continue to be made to provide MRE to reach less educated couples.

Additionally, the finding that those who are less materialistic are more likely to turn to self-directed MRE suggests that the lower cost of self-directed MRE may be appealing to some couples. We should continue to make affordable self-directed MRE available to reach this audience.

The finding that religiosity impacts self-directed MRE and traditional MRE participation aligns with past research connecting religiosity with higher rates of MRE participation (Halford et al., 2004; Stanley et al., 2006). This suggests that the religious are highly motivated to seek out MRE, probably because marriage is sacred to them. The question arises how to attract the nonreligious while continuing to support the religious who will likely participate more frequently. Perhaps marketing is a key here; promoting the benefits of MRE might encourage those who are not motivated by religious reasons to still seek it out in order to benefit their relationships.

I anticipated finding evidence that more at-risk couples seek out self-directed MRE. The data did not support this. Although this goes against the research of Doss et al. (2009), this finding is in line with other investigations of marriage preparation programs as a whole (Duncan et al., 2007; Halford et al., 2006; Stanley et al., 2006). Often researchers despair that we are not 
reaching more at-risk couples. However, I echo Duncan et al.'s (2007) concern that we do not neglect healthy couples who seek MRE. If these couples access our programs, we need to provide materials which meet their unique needs. Thus, self-directed MRE should not focus on problem-solving in relationships alone, but also on how to strengthen healthy relationships.

While the data did not suggest that at-risk couples per se sought out self-directed MRE, it was interesting to note that those with more neurotic partners were more likely to turn to selfdirected MRE, while those with less neurotic partners were more likely to turn to traditional MRE methods. As noted previously, this may be due to the fact that traditional MRE is more often experienced as a couple, rather than on the individual level; it may be difficult to convince a neurotic partner to attend a class or workshop. Self-directed MRE should be provided to address the unique needs of those partnered with neurotic individuals to assist them in keeping their relationships strong and in coping with their partners' neuroses.

\section{Limitations and Directions for Future Research}

My research was limited in that it was cross- sectional, which means that temporal ordering of events were not possible. Thus it was not clear whether these factors predicted MRE participation or came as a result of the intervention. However, for the majority of factors of selfdirected MRE participation, it was not plausible that the intervention caused the factors (for example, the intervention could not cause a participant to be older or more educated). Future research should examine MRE participation from a longitudinal perspective to further explore this issue.

A further limitation concerns the collection of data. Data was collected using the RELATE questionnaire, which can arguably be itself a form of self-directed MRE. Participants understood that questions about self-directed participation referred to forms outside the RELATE 
questionnaire, and as they had not yet received the readout from the questionnaire, they had not yet received the self-directed MRE the questionnaire provides. Yet the question arises who is turning to RELATE. By virtue of taking the RELATE questionnaire, all participants were involved in some level of MRE. In best practices MRE, self and other assessments are important strategies (see Childs \& Duncan, in press). The process that leads couples to participate in RELATE is fairly selective, and those couples who never participate in MRE are not included in the data collected using this measure. Future research might consider collecting the data using another instrument which is not a potential confound. Indeed, this method of data collection could have influenced the variance I was able to predict. Additionally, it is unknown whether RELATE participants view it as a self-directed intervention or not. There is generally no educational intervention associated with RELATE, so it may not be seen as MRE, but as an assessment only.Future research could address this issue. I note that only 672 members of our sample reported accessing self-directed education outside of RELATE, which suggests that the majority of the sample did not commonly consume self-directed MRE materials. There was enough variation in MRE participation within the sample to justify using it for this study.

Additionally, this study is limited in that it is not highly generalizable. The majority of the sample was Caucasian and well-educated; more research needs to be done involving ethnic minorities and lower socioeconomic status individuals. In addition, particularly in the traditional MRE participation group, Latter-day Saint college students were overrepresented, probably a result of RELATE being sponsored by Brigham Young University. A more diverse sample of traditional MRE participants might yield different results.

Finally, the small $R^{2}$ s found in the analyses suggest that this study only gets at a small piece of the variance involved in self-directed and traditional MRE attendance. More factors are 
involved which were not touched on here, including perhaps issues of time, cost, and access to MRE, as well as individual preferences for privacy or a group learning format. Future research should continue to explore this issue in more detail in order to better understand what factors influence MRE participation in its various formats.

\section{Conclusion}

This study provides some evidence that self-directed MRE and traditional MRE reach different audiences. In particular, self-directed MRE appears to be reaching those who are older, more educated, more religious, less materialistic, and who have been together for a shorter length of time. However, the variance accounted for by these factors is small. More research remains to be done to determine what other factors influence participation in self-directed MRE. In particular, future research should approach the topic from a longitudinal perspective, using a more representative sample. Nevertheless, my results give some insight into the audience currently accessing these materials. Self-directed MRE should be available to meet the needs of these specific individuals; in addition efforts should continue to be made to expand self-directed MRE to reach a wider audience.

As the internet has changed the way information is shared, there is an increasing expectation that information is available anywhere, at any time. As such, I expect to see more development of self-directed programs. Coming to understand who is accessing these programs will help us determine if self-directed materials truly have the potential to reach a larger, or at least different, audience than traditional education. 


\section{References}

Anderson, L. D. (1984). The effects of a home-based, audio cassette marriage enrichment course on marital communication and marital adjustment (Doctoral dissertation, North Texas State University, 1984). Dissertation Abstract International, 45, 1989A.

Blair, J. M., \& Cordova, J. V. (2009). Commitment as a predictor of participation in premarital education. The Family Journal, 17, 118-125.

Braithwaite, S., \& Fincham, F. (2007). ePREP: Computer based prevention of relationship dysfunction, depression and anxiety. Journal of Social and Clinical Psychology, 26(5), $609-622$.

Braithwaite, S. R., \& Fincham, F. D. (2009). A randomized clinical trial of a computer based preventative intervention: Replication and extension of ePREP. Journal of Family Psychology, 23, 32-38.

Burns, R. P, \& Burns, R. (2008). Business research methods and statistics using SPSS. Thousand Oaks, CA: SAGE Publications Inc.

Busby, D. M., Holman, T. B., \& Taniguchi, N. (2001). RELATE: Relationship evaluation of the individual, family, cultural, and couple contexts. Family Relations, 50, 308-316.

Busby, D. M., Ivey, D. C., Harris, S. M., \& Ates, C. (2007). Self-directed, therapist-directed, and assessment-based interventions for premarital couples. Family Relations, 56, 279-290.

Casey, L. M., \& Halford, W. K. (2010). Couples and the silicon chip: Applying information technology to couple relationship services. In K. Hahlweg, M. Graw-Gerber, \& D. H. Baucom (Eds.), Enhancing couples: The shape of couple therapy to come (pp. 216-230). Cambridge, MA: Hogrefe Publishing. 
Childs, G. R., \& Duncan, S. F. (in press). Marriage preparation education programs: An assessment of their components. Marriage and Family Review.

DeMaria, R. (2005). Distressed couples and marriage education. Family Relations, 54, 242-254.

Doss, B. (2009). Expanding the reach and effectiveness of marital interventions. In H. Benson and S. Callan (Eds.), What works in relationship education: Lessons from academics and service deliverers in the United States and Europe (pp. 75 - 86). Doha, Qatar: Doha International Institute for Family Studies and Development.

Doss, B. D., Rhoades, G. K., Stanley, S. M., \& Markman, H. J. (2009). Marital therapy, retreats, and books: The who, what, when, and why of relationship help-seeking. Journal of Marital and Family Therapy, 35, 18-29.

Doss, B. D., Rhoades, G. K., Stanley, S. M., Markman, H. J., \& Johnson, C. A. (2009). Differential use of premarital education in first and second marriages. Journal of Family Psychology, 23, 268-273.

Duncan, S. F., Box, G., \& Silliman, B. (1996). Racial and gender effects on perceptions of marriage preparation programs among college-educated young adults. Family Relations, 45, 80-90.

Duncan, S. F., Childs, G. R., \& Larson, J. H. (2010). Perceived helpfulness of four different types of marriage preparation interventions. Family Relations, 59, 623-636.

Duncan, S. F., \& Goddard, H. W. (2011). Family life education: Principles and practices for effective outreach ( $2^{\text {nd }}$ ed.). Thousand Oaks, CA: Sage.

Duncan, S. F., Holman, T. B., \& Yang, C. (2007). Factors associated with involvement in marriage preparation programs. Family Relations, 56, 270-278. 
Duncan, S. F., Steed, A., \& Needham, C. M. (2009). A comparison evaluation study of webbased and traditional marriage and relationship education. Journal of Couple and Relationship Therapy, 8, 162-180.

Ebata, A. T., \& Dennis, S. A. (2011). Family life education on the technological frontier. In S.F. Duncan \& H. W. Goddard (Eds.), Family life education: Principles and practices for effective outreach $\left(2^{\text {nd }}\right.$ ed.). Thousand Oaks, CA: Sage.

Ellison, C. G., Burdette, A. M., \& Glenn, N. D. (2011). Praying for Mr. Right? Religion, family background, and marital expectations among college women. Journal of Family Issues, 32(7), 906-931.

Fincham, F. D., Stanley, S. M., \& Rhoades, G. K. (2011). Relationship education in emerging adulthood: Problems and prospects. In F. D. Fincham \& M. Cui (Eds.), Romantic relationships in emerging adulthood (pp.293-316). New York: Cambridge University Press.

Geraghty, A., Wood, A., \& Hyland, M. (2010). Attrition from self-directed interventions: Investigating the relationship between psychological predictors, intervention content and dropout from a body dissatisfaction intervention. Social Science and Medicine, 71, 30-37.

Gottman, J. M. (1999). The seven principles for making marriage work. New York: Crown.

Gottman, J. M., Ryan, K., Swanson, C., \& Swanson, K. (2005). Proximal change experiments with couples: A methodology for empirically building a science of effective interventions of changing couples' interaction. Journal of Family Communication, 5, 163-190. 
Gray, J. (1993). Men are from Mars, women are from Venus: A practical guide for improving communication and getting what you want in your relationships. New York: HarperCollins.

Halford, W. K., \& Casey, L. M. (2010). Taking it to the people: Using technology to enhance the impact of couple relationship education. In K. Hahlweg, M. Grawe-Gerber, \& D. H. Baucom (Eds.), Enhancing couples: The shape of couple therapy to come (pp. 111-127). Cambridge, MA: Hogrefe Publishing.

Halford, W. K., Moore, E., Wilson, K. L., Farrugia, C., \& Dyer, C. (2004). Benefits of flexible delivery relationship education: An evaluation of the CoupleCARE program. Family Relations, 53, 469-476.

Halford, W., O'Donnell, C., Lizzio, A., \& Wilson, K. (2006). Do couples at high risk of relationship problems attend premarriage education?. Journal of Family Psychology, 20, 160-163.

Halford, W., Wilson, K., Watson, B., Verner, T., Larson, J., Busby, D., et al. (2010). Couple relationship education at home: Does skill training enhance relationship assessment and feedback?. Journal of Family Psychology, 24, 188-196.

Hawkins, A. J. (2011). Facilitating forever: A 50-State Profile of government efforts to help couples form and sustain healthy marriages. Working manuscript, Brigham Young University, Provo, Utah.

Hawkins, A. J., Blanchard, V. L., Baldwin, S. A., \& Fawcett, E. B. (2008). Does marriage and relationship education work? A meta-analytic study. Journal of Consulting and Clinical Psychology, 76, 723-734. 
Hawkins, A. J., Carroll, J. S., Doherty, W. J., \& Willoughby, B. (2004). A comprehensive framework for marriage education. Family Relations, 53, 547-558.

Hawkins, A. J., Fawcett, E. B., Carroll, J. S., \& Gilliland, T. T. (2006). The Marriage Moments program for couples transitioning to parenthood: Divergent conclusions from formative and outcome evaluation data. Journal of Family Psychology, 20, 561-570.

Hawkins, A. J., \& Ooms, T. (2010). What works in relationship and marriage education? A review of lessons learned with a focus on low-income couples. In Healthy Marriage Resource Center. Retrieved from http://www.healthymarriageinfo.org/resourcedetail/index.aspx?rid=2861

Holman and Associates. (2001). Premarital prediction of marital quality or break up. New York: Kluwer Academic/Plenum.

Johnson, V. I. (2011). Adult children of divorce and relationship education: Implications for counselors and counselor educators. The Family Journal, 19(1), 22-29.

Jose, A., O’Leary, K. D., \& Moyer, A. (2010). Does premarital cohabitation predict subsequent marital stability and marital quality? A meta-analysis. Journal of Marriage and Family, 72, $105-116$.

Kalinka, C. J., Fincham, F. D., \& Hirsch, A. H. (2012). A randomized clinical trial of a selfpaced, online relationship education intervention for new and expectant parents. Journal of Family Psychology, 26, 159-164.

Karney, B. R., \& Bradbury, T. N. (1997). Neuroticism, marital interaction, and the trajectory of marital satisfaction. Journal of Personality and Social Psychology, 72, 1075-1092.

Kennedy, T., Smith, A., Wells, A. T., \& Wellman, B. (2008). Networked families (Pew Internet \& American Life Project). Available from http://www.pewinternet.org/ 
Klemer, R. H., \& Smith, R. M. (1975). Teaching about family relationships. Minneapolis, MN: Burgess.

L'Abate, L. (1983). Prevention as a profession: Toward a new conceptual frame of reference. In D. R. Mace (Ed.) Prevention in family services: Approaches to family therapy and counseling (pp. 46-52). Beverly Hills, CA: Sage.

Larson, J. H., Blick, R. W., Jackson, J. B., \& Holman, T. B. (2010). Partner traits that predict relationship satisfaction for neurotic individuals in premarital relationships. Journal of Sex and Marital Therapy, 36, 430-444.

Larson, J. H., Vatter, R. S., Galbraith, R. C., Holman, T. B., \& Stahmann, R. F. (2007). The RELATionship Evaluation (RELATE) with therapist-assisted interpretation: Short-term effects on premarital relationships. Journal of Marital and Family Therapy, 33, 364-374.

Markiewicz, D., Lawford, H., Doyle, A., \& Haggart, N. (2006). Developmental differences in adolescents' and young adults' use of mothers, fathers, best friends, and romantic partners to fulfill attachment needs. Journal of Youth and Adolescence, 35, 127-140.

Markman, H. J., Rhoades, G. K., Delaney, R., White, L., \& Pacifici, C. (2010). Extending the reach of research-based couples interventions. In K. Hahlweg, M. Grawe-Gerber, \& D. H. Baucom (Eds.), Enhancing couples: The shape of couple therapy to come (pp. 128-141). Cambridge, MA: Hogrefe Publishing.

Markman, H. J., Stanley, S. M., \& Blumberg, S. L. (2010). Fighting for your marriage: A deluxe revised edition of the classic best-seller for enhancing marriage and preventing divorce. San Francisco: Jossey-Bass. 
Marshall, J. P. (2005). Saying I do. Retrieved from Utah State University, http://ocw.usu.edu/Family_Consumer___Human_Development/Marriage__Family_R elationships/index.html.

McAllister, S., Duncan, S. F., \& Hawkins, A. J. (in press). Examining the early evidence for selfdirected marriage and relationship education: A meta-analytic study. Family Relations.

Morris, M. L., McMillan, H.S. , Duncan, S.F. \& Larson, J.H.(2011). Who will attend? Characteristics of couples and individuals in marriage education. Marriage \& Family Review, 47, 1-22.

Olson, D. H., Larson, P. H., \& Olson-Sigg, A. (2009). Couple Checkup: Tuning up your relationships. Journal of Couple \& Relationship Therapy, 8, 129-142.

Olson, D. H., \& Olson, A. K. (2000). Empowering couples: PREPARE/ENRICH Program. Marriage \& Family: A Christian Journal, 3(1), 69-81.

Owen, J., Rhoades, G. K., Stanley, S. M., \& Markman, H. J. (2011). The role of leaders' working alliance in premarital education. Journal of Family Psychology, 25, 49-57.

Prensky, M. (2001). Digital natives, digital immigrants. On the Horizon, 9 (5).

Ramsay, A. J. (1989). Marriage enrichment: The use of computers to teach communication skills (Doctoral dissertation, University of North Texas, 1989). Dissertation Abstracts International, 50, 2390A.

Rusbult, C. E., Lange, P. A., Wildschut, T., Yovetich, N. A., \& Verette, J. (2000). Perceived superiority in close relationships: Why it exists and persists. Journal of Personality and Social Psychology, 79, 521-545. 
Saiz, C. C. (2001). Teaching couples communication and problem-solving skills: A self-directed, videotaped version of the prevention relationship enhancement program (PREP) (Doctoral dissertation, University of Denver, 2001). Dissertation Abstracts International, 62, 2076B.

Schmeida, M., \& McNeal, R. (2007). The telehealth divide: Disparities in searching public health information online. Journal of Health Care for the Poor and Underserved, 18, 637-647.

Silliman, B., Stanley, S. M., Coffin, W., Markman, H. J., \& Jordan, P. L. (2002). Preventive interventions for couples. In H. A.Liddle, D. A.Santisteban, R. F.Levant, \& J. H.Bray (Eds.), Family psychology: Science-based interventions (pp. 123-146). Washington, DC: American Psychological Association.

Sroufe, L. A., Egeland, B., Carlson, E. A., \& Collins, W. A. (2009). The development of the person: The Minnesota study of risk and adaptation from birth to adulthood. New York: The Guilford Press.

Stanley, S. M., Allen, E. S., Markman, H. J., Rhoades, G. K., \& Prentice, D. L. (2010). Decreasing divorce in U.S. army couples: Results from a randomized controlled trial using PREP for Strong Bonds. Journal of Couple and Relationship Therapy, 9, 149-160.

Stanley, S. M., Amato, P. R., Johnson, C. A., \& Markman, H. J. (2006). Premarital education, marital quality, and marital stability: Findings from a large, random household survey. Journal of Family Psychology, 20, 117-126.

Taylor, C., Jobson, K. O., Winzelberg, A., \& Abascal, L. (2002). The use of the Internet to provide evidence-based integrated treatment programs for mental health. Psychiatric Annals, 32, 671-677. 
Thornton, A. (1991). Influence of the marital history of parents on the marital and cohabitational experiences of children. American Journal of Sociology, 96, 868-894.

U.S. Department of Commerce. (2010). Digital Nation: 21st century America's progress toward universal broadband internet access. Washington, D.C.: U.S. Department of Commerce, National Telecommunications and Information Administration Retrieved from http://www.ntia.doc.gov/reports/2010/NTIA_internet_use_report_Feb2010.pdf.

Walker, S. K., \& Greenhow, C. (2008, November). What Facebook tells us about the future (and present) of parent and family education. Paper presented at the annual meeting of the National Council on Family Relations, Little Rock, AR.

Whisman, M. A., Uebelacker, L. A., \& Weinstock, L. M. (2004). Psychopathology and marital satisfaction: The importance of evaluating both partners. Journal of Consulting and Clinical Psychology, 72, 830-838.

Wilcox, W. B. \& Marquardt, E. (2010). The state of our unions 2010: When marriage disappears: The new middle America. Piscataway, NJ: The National Marriage Project. Retrieved 31 May 2011 from http://www.virginia.edu/marriageproject/pdfs/Union_11_12_10.pdf.

Wilson, K. L., \& Halford, W. K. (2008). Processes of change in self-directed couple relationship education. Family Relations, 57, 625-635.

Worthington, E. L., Jr., McCullough, M. E., Shortz, J. L., Mindes, E. J., Sandage, S. J., \& Chartrand, J. M. (1995). Can couples assessment and feedback improve relationships? Assessment as a brief relationship enrichment procedure. Journal of Counseling Psychology, 42, 466-475. 
Yamauchi, H., \& Ito, H. (2008). Parents' marital relationship and adolescents' attitudes toward marriage. Japanese Journal of Developmental Psychology, 19, 294-304. 
Table 1. Logistic regression coefficients, standard errors, Wald statistics, and odds ratios

\begin{tabular}{|c|c|c|c|c|c|c|c|c|}
\hline \multirow{2}{*}{$\begin{array}{l}\text { Independent } \\
\text { Variables }\end{array}$} & \multicolumn{4}{|c|}{ Self-Directed MRE } & \multicolumn{4}{|c|}{ Traditional MRE } \\
\hline & $\mathrm{B}$ & S. E. & Wald & O.R. & $\mathrm{B}$ & S. E. & Wald & O.R. \\
\hline \multicolumn{9}{|l|}{ Individual Factors } \\
\hline Extroversion & 0.004 & 0.061 & .005 & 1.004 & 0.052 & 0.043 & 1.404 & 1.053 \\
\hline Partner's extroversion & -0.059 & .056 & 1.103 & 0.943 & -0.013 & 0.041 & 0.108 & 0.987 \\
\hline Flexibility & 0.055 & 0.091 & 0.362 & 1.056 & 0.023 & 0.065 & 0.122 & 1.023 \\
\hline Partner's flexibility & -0.037 & 0.085 & 0.192 & 0.964 & 0.061 & 0.062 & 0.967 & 1.063 \\
\hline Kindness & 0.140 & 0.098 & 2.026 & 1.15 & $-0.149 *$ & 0.070 & 4.541 & 0.861 \\
\hline Partner's kindness & -0.112 & 0.090 & 1.530 & 0.894 & $0.227 * * *$ & 0.070 & 10.593 & 1.255 \\
\hline Neuroticism & 0.102 & 0.087 & 1.353 & 1.107 & -0.024 & 0.064 & 0.136 & 0.977 \\
\hline Partner's neuroticism & $0.201 * *$ & 0.078 & 6.633 & 1.223 & $-0.196^{* * *}$ & 0.059 & 11.108 & 0.822 \\
\hline $\begin{array}{l}\text { Importance of } \\
\text { marriage }\end{array}$ & -0.047 & $\begin{array}{l}0.069 \\
0.064\end{array}$ & 0.478 & 0.954 & $0.507 * * *$ & $\begin{array}{l}0.052 \\
0.045\end{array}$ & 94.516 & 1.660 \\
\hline Materialism & $-0.156^{*}$ & & 5.981 & 0.856 & -0.007 & & 0.025 & 0.993 \\
\hline Religiosity & $0.296 * * *$ & 0.049 & 35.703 & 1.344 & $0.279 * * *$ & 0.036 & 59.071 & 1.321 \\
\hline $\begin{array}{l}\text { Couple Factors } \\
\text { Negative }\end{array}$ & & & & & & & & \\
\hline $\begin{array}{l}\text { communication (self) } \\
\text { Positive }\end{array}$ & -0.012 & 0.124 & 0.010 & 0.988 & 0.038 & 0.086 & 0.200 & 1.039 \\
\hline communication (self) & 0.024 & 0.137 & 0.032 & 1.025 & 0.045 & 0.096 & 0.223 & 1.046 \\
\hline $\begin{array}{l}\text { Negative } \\
\text { communication } \\
\text { (partner) }\end{array}$ & 0.000 & 0.105 & 0.000 & 1.000 & -0.258 & 0.075 & 11.839 & 0.773 \\
\hline $\begin{array}{l}\text { Positive } \\
\text { communication } \\
\text { (partner) }\end{array}$ & -0.010 & 0.126 & 0.006 & 0.990 & $0.253 * *$ & 0.089 & 8.062 & 1.288 \\
\hline Relationship length & $-0.164 * * *$ & 0.039 & 17.576 & 0.848 & $-0.210 * * *$ & 0.026 & 65.170 & 0.810 \\
\hline Relationship stability & 0.087 & 0.080 & 1.178 & 1.091 & 0.009 & 0.057 & 0.024 & 1.009 \\
\hline
\end{tabular}




\begin{tabular}{|c|c|c|c|c|c|c|c|c|}
\hline \multirow{2}{*}{$\begin{array}{l}\text { Independent } \\
\text { Variables }\end{array}$} & \multicolumn{4}{|c|}{ Self Directed MRE } & \multicolumn{4}{|c|}{ Traditional MRE } \\
\hline & $\mathrm{B}$ & S. E. & Wald & O.R. & $\mathrm{B}$ & S. E. & Wald & O.R. \\
\hline \multicolumn{9}{|l|}{ Family Factors } \\
\hline $\begin{array}{l}\text { Impact of family of } \\
\text { origin }\end{array}$ & 0.063 & 0.048 & 1.691 & 1.065 & $-0.107 * *$ & 0.035 & 9.054 & 0.899 \\
\hline Parents' marriage & -0.052 & 0.040 & 1.687 & 0.949 & $0.113 * * *$ & 0.028 & 16.072 & 1.120 \\
\hline Relationship with & $-0101 *$ & 0.046 & 4703 & 0904 & $0101 * *$ & 0036 & 7809 & 1107 \\
\hline Relationship with & -0058 & 0045 & 1679 & 0943 & $0075 *$ & 0033 & 5233 & 1078 \\
\hline \multicolumn{9}{|c|}{ Sociocultural Factors } \\
\hline Age & $0.028 * * *$ & 0.004 & 52.228 & 1.028 & $-0.049 * * *$ & 0.004 & 164.006 & 0.952 \\
\hline Education & $0.107 * * *$ & 0.023 & 21.789 & 1.113 & $-0.036^{*}$ & 0.017 & 4.450 & 0.965 \\
\hline African & 0.600 & 0.431 & 1.943 & 1.823 & $-0.500 \dagger$ & 0.275 & 3.293 & 0.607 \\
\hline Asian & 0.015 & 0.450 & 0.001 & 1.015 & -0.335 & 0.267 & 1.571 & 0.716 \\
\hline Caucasian & 0.547 & 0.392 & 1.945 & 1.727 & 0.117 & 0.219 & 0.284 & 1.124 \\
\hline Native American & -0.796 & 1.085 & 0.538 & 0.451 & -0.214 & 0.448 & 0.228 & 0.807 \\
\hline Latino & 0.427 & 0.444 & 0.926 & 1.533 & -0.147 & 0.260 & 0.320 & 0.863 \\
\hline Mixed/Biracial & 0.418 & 0.468 & 0.797 & 1.519 & 0.237 & 0.266 & 0.794 & 1.267 \\
\hline
\end{tabular}

Notes: All Ethnicities are dummy coded, with other as the reference category. $\dagger p<.1{ }^{*} \mathrm{p}<.05 .{ }^{* *} \mathrm{p}<.01 .{ }^{* * *} \mathrm{p}<.001$. 